ARTICLE

\title{
Poly(fluorenyl aryl piperidinium) membranes and ionomers for anion exchange membrane fuel cells
}

Nanjun Chen (1) 1,5, Ho Hyun Wang ${ }^{1,5}$, Sun Pyo Kim¹, Hae Min Kim¹, Won Hee Lee ${ }^{1}$, Chuan Hu', Joon Yong Bae', Eun Seob Sim², Yong-Chae Chung ${ }^{2}$, Jue-Hyuk Jang ${ }^{3}$, Sung Jong Yoo (i) ${ }^{3}$, Yongbing Zhuang (i) ${ }^{4} \&$

Young Moo Lee (i) ${ }^{1 凶}$

Low-cost anion exchange membrane fuel cells have been investigated as a promising alternative to proton exchange membrane fuel cells for the last decade. The major barriers to the viability of anion exchange membrane fuel cells are their unsatisfactory key componentsanion exchange ionomers and membranes. Here, we present a series of durable poly(fluorenyl aryl piperidinium) ionomers and membranes where the membranes possess high $\mathrm{OH}^{-}$ conductivity of $208 \mathrm{mS} \mathrm{cm}^{-1}$ at $80^{\circ} \mathrm{C}$, low $\mathrm{H}_{2}$ permeability, excellent mechanical properties (84.5 MPa TS), and $2000 \mathrm{~h}$ ex-situ durability in $1 \mathrm{M} \mathrm{NaOH}$ at $80^{\circ} \mathrm{C}$, while the ionomers have high water vapor permeability and low phenyl adsorption. Based on our rational design of poly (fluorenyl aryl piperidinium) membranes and ionomers, we demonstrate alkaline fuel cell performances of $2.34 \mathrm{~W} \mathrm{~cm}^{-2}$ in $\mathrm{H}_{2}-\mathrm{O}_{2}$ and $1.25 \mathrm{~W} \mathrm{~cm}^{-2}$ in $\mathrm{H}_{2}$-air $\left(\mathrm{CO}_{2}\right.$-free $)$ at $80^{\circ} \mathrm{C}$. The present cells can be operated stably under a $0.2 \mathrm{~A} \mathrm{~cm}^{-2}$ current density for $\sim 200 \mathrm{~h}$.

\footnotetext{
${ }^{1}$ Department of Energy Engineering, College of Engineering, Hanyang University, Seoul, Republic of Korea. ${ }^{2}$ Department of Materials Science and Engineering, College of Engineering, Hanyang University, Seoul, Republic of Korea. ${ }^{3}$ Hydrogen Fuel Cell Research Center, Korea Institute of Science and Technology (KIST), Seoul, Republic of Korea. ${ }^{4}$ State Key Laboratory of Biochemical Engineering, Institute of Process Engineering, University of Chinese Academy of Sciences, Chinese Academy of Sciences, Beijing, PR China. ${ }^{5}$ These authors contributed equally:Nanjun Chen,Ho Hyun Wang. ${ }^{凶}$ email: ymlee@hanyang.ac.kr
} 
nion exchange membrane fuel cells (AEMFCs) have made significant advances, especially in power density, that represents a parallel track to proton exchange membrane fuel cells (PEMFCs) ${ }^{1-3}$. Operating in alkaline environments, AEMFCs possess evident cost advantages due to the possibility of using non-platinum group metal (non-PGM) catalysts. AEMFCs intend to address high-cost issues associated with PEMFCs and to raise the economic competitiveness of low-temperature fuel cells with other power generation technologies in many burgeoning areas, particularly in light-duty transportation ${ }^{4-8}$. However, the major barriers to the viability of AEMFCs are their key but unsatisfactory materials including anion exchange polyelectrolytes (AEPs), which can be used both as anion exchange ionomers (AEIs) and membranes (AEMs) ${ }^{9-12}$. AEPs consist of polymer backbones and the pendent cationic groups that act as ion transporting species to conduct $\mathrm{OH}^{-}$and to transport water molecules ${ }^{13-16}$. Although numerous cationic groups (ammonium ${ }^{17}$, imidazolium ${ }^{15,16}$, phosphonium $^{18}$, sulfonium $^{19}$, and organometallic cation ${ }^{20,21}$ ) and polymer backbones ${ }^{22-28}$ have been employed in AEPs so far, only a few AEPs display satisfactory performance at high $\mathrm{pH}$ and temperature $\left(>80^{\circ} \mathrm{C}\right)^{17,29-33}$.

To date, years of study have revealed that the ammonium group has been the most-studied cationic group for AEPs due to its high ion conductivity, durability, and practicability. Moreover, the discovery of aryl ether-free AEPs addressed several early-stage problems of AEMs, such as low ion conductivity, insufficient alkaline stability, and poor mechanical properties ${ }^{17,29,32}$. Three types of aryl ether-free AEPs are dominant in AEMFCs so far: benzyl trimethylammonium (BTMA) ${ }^{12,29,30}$, alkyl ammonium ${ }^{10,34,35}$, and dimethylpiperidinium (DMP)-type AEPs $17,32,36$. Wang et al. ${ }^{29}$ reported an AEMFC based on BTMA-type poly(ethylene-co-tetrafluoroethylene) (BTMA-ETFE) ionomers and high-density polyethylene (BTMA-HDPE) AEMs that reached a peak power density (PPD) over $2 \mathrm{~W} \mathrm{~cm}^{-2}$ at $80^{\circ} \mathrm{C}$ in $\mathrm{H}_{2}-\mathrm{O}_{2}$ with a $0.70 \mathrm{mg} \mathrm{cm}^{-2}$ $\mathrm{Pt}-\mathrm{Ru} / \mathrm{C}$ anode. Mandal et al. ${ }^{31,33}$ reported that $\mathrm{H}_{2}-\mathrm{O}_{2}$ AEMFCs based on BTMA-ETFE ionomers and PTFE-reinforced poly(norbornene) (PNB) AEMs reached a PPD over $3 \mathrm{~W} \mathrm{~cm}^{-2}$ at $80^{\circ} \mathrm{C}$ with a $0.70 \mathrm{mg} \mathrm{cm}^{-2} \mathrm{Pt}-\mathrm{Ru} / \mathrm{C}$ anode. However, BTMA-ETFE possessed poor alkaline stability because the BTMA-ETFE membrane was brittle after being soaked in $1 \mathrm{M} \mathrm{NaOH}$ at $80^{\circ} \mathrm{C}$ for only $168 \mathrm{~h}^{12}$. Lee et $\mathrm{al}^{35}$ and Maurya et al. ${ }^{34}$ reported alkyl ammonium poly (terphenylene) AEMs and alkyl ammonium fluorene ionomers.
Alkyl ammonium-type AEPs ${ }^{34,37}$ exhibited preferable alkaline stability (stable in $1 \mathrm{M} \mathrm{NaOH}$ at $80^{\circ} \mathrm{C}$ for $720 \mathrm{~h}$ ) compared to BTMA-type AEPs, while the PPD of these AEMFCs was limited to below $1.6 \mathrm{~W} \mathrm{~cm}^{-2}$. Wang et al. ${ }^{17}$ also reported stable poly (biphenyl piperidinium) (PFBP-0) ionomers and copoly(aryl piperidinium) (c-PAP) AEMs. Their $\mathrm{H}_{2}-\mathrm{O}_{2}$ AEMFCs reached a PPD of $1.89 \mathrm{~W} \mathrm{~cm}^{-2}$ with a $0.7 \mathrm{mg} \mathrm{cm}^{-2} \mathrm{Pt}-\mathrm{Ru} / \mathrm{C}$ anode. However, biphenyl or terphenyl groups in PAP AEIs have been documented to possess high phenyl adsorption on catalysts ${ }^{34,37-39}$. Currently, AEI research has been highlighted as a crucial issue by the latest US Department of Energy (DOE) protocol for the next decade. However, we lack sufficient insight from ionomer research, which has not revealed the effects of water vapor transport behavior and molecular dimensions of AEIs on the cell performance.

Here, we present poly(fluorenyl aryl piperidinium) (PFAP) copolymers for AEMs and AEIs. The fluorene (FLN) segment in the copolymers improves the rigidity and phase-separated morphology of AEMs to increase the dimensional stability and ion conductivity. Moreover, AEIs with rigid FLN groups are expected to improve the water vapor permeability (or water diffusivity) and decrease the phenyl adsorption effect.

\section{Results}

Design of polymers and characterization. Our PFAP copolymers were synthesized by a facile acid-catalyzed condensation reaction (Supplementary Fig. 1). Poly(fluorene-co-biphenyl N,N'-dimethylpiperidinium) (PFBP- $x$ ) and poly(fluorene N,N-dimethylpiperidinium-co-nonafluoride) (PFPN- $x$ ) are designed for AEIs (Fig. 1a, b), whereas poly(fluorene-co-terphenyl N,N'-dimethylpiperidinium) (PFTP- $x$ ) is specifically considered for AEMs (Fig. 1c). Here, $x$ is the molar ratio of the fluorenyl piperidinium segment in the copolymer. Structural analysis of PFAP- $x$ can be confirmed by ${ }^{1} \mathrm{H}$ nuclear magnetic resonance $\left({ }^{1} \mathrm{H} \mathrm{NMR}\right)$ spectra (Supplementary Figs. 2-12).

PFAP AEIs were rationally designed to combine the merits of currently representative BTMA-ETFE ${ }^{29,30}$, alkyl ammonium $\mathrm{PF}^{34}$, and PAP ionomers ${ }^{17,36}$, and overcome their drawbacks. They have advantages including (1) PFBP AEIs containing DMP and FLN groups possess high ex-situ durability, rigidity, and low ionomer phenyl adsorption. Torsional rotation calculations demonstrated that FLNs had much smaller dihedral angle in the optimized

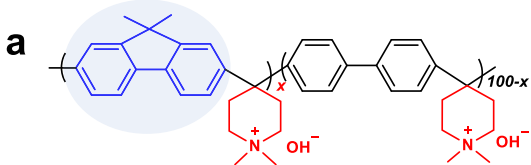

PFBP-x: Rigid and high water-permeable AEls Reasonable molecular weight

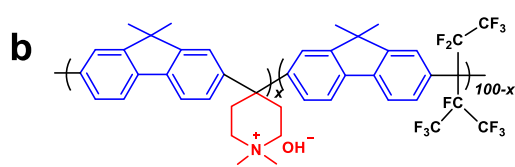

PFPN-x. Rigid but low molecular weight AEls

PFBP-0, IEC: $3.52 \mathrm{mmol} \mathrm{g}^{-1},[\eta]$ ]: $5.23 \mathrm{dL} \mathrm{g}^{-1}$ PFBP-14, IEC: $3.43 \mathrm{mmol} \mathrm{g}^{-1}$, [n]: $2.34 \mathrm{dL} \mathrm{g}^{-1}$ PFBP-30, IEC: $3.35 \mathrm{mmol} \mathrm{g}^{-1}$, [n]: $1.16 \mathrm{dL} \mathrm{g}^{-1}$ PFBP-50, IEC: $3.27 \mathrm{mmol} \mathrm{g}^{-1}$, [n]: $0.48 \mathrm{dL} \mathrm{g}^{-1}$

PFPN-100, IEC: $3.09 \mathrm{mmol} \mathrm{g}^{-1}$, [n]: $0.28 \mathrm{dL} \mathrm{g}^{-1}$ PFPN-85, IEC: $2.86 \mathrm{mmol} \mathrm{g}^{-1}$, [门]: $0.38 \mathrm{dL} \mathrm{g}^{-1}$.

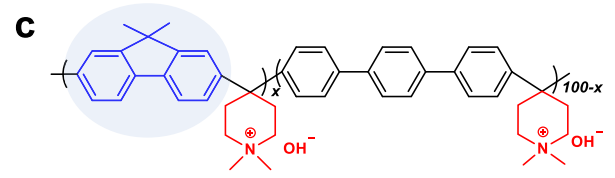

PFTP-x: Rigid and robust AEMs High molecular weight

PFTP-0, IEC: $2.78 \mathrm{mmol} \mathrm{g}^{-1},[\eta]$ ]: $4.88 \mathrm{dL} \mathrm{g}^{-1}$. PFTP-13, IEC: $2.81 \mathrm{mmol} \mathrm{g}^{-1}$, [n]: $4.08 \mathrm{dL} \mathrm{g}^{-1}$ 
geometry along with higher rotation energy barrier than biphenyl and terphenyl groups (Supplementary Fig. 13), implying the high rigidity of FLNs ${ }^{40}$. Density functional theory (DFT) calculations revealed that FLN-based molecules have lower phenyl adsorption energies than those of biphenyl-based molecules on Pt or Pt-Ru (111) crystal planes (Supplementary Fig. 14). (2) PFAP AEIs possess better solubility than ordinary PFBP-0 and PFTP-0 ionomers due to the presence of rigid FLN groups. Solubility testing of these polymers demonstrated that PFBP ionomers showed the best solubility in IPA/DI water (Supplementary Table 1), which is beneficial for catalyst slurry preparation.

As for the advantages of PFAP AEMs, (1) FLNs increase the rigidity of PFTP AEMs, which simultaneously improves the ionconducting capability and dimensional stability (Supplementary Fig. 15). PFTP-13 AEMs with high IEC show lower water SRs than those of PFTP-0 AEMs (Supplementary Table 2). (2) PFAP copolymers have facile synthetic processes (two steps, no heating, short synthetic period). PFAP AEIs and AEMs possess significantly different intrinsic viscosities ([n]) depending on the FLN content (Supplementary Table 3), which is related to the differences in their molecular weights. PFBP-14 $\left(2.32 \mathrm{dL} \mathrm{g}^{-1}\right)$, PFTP-13 (4.08 dL g $\left.{ }^{-1}\right)$, PFBP-0 $\left(5.25 \mathrm{dL} \mathrm{g}^{-1}\right)$, and PFTP-0 $\left(4.875 \mathrm{dL} \mathrm{g}^{-1}\right)$ possess a high $[\mathrm{n}]$ that provides excellent filmforming properties. PFAP- $x$ and PFPN- $x$ copolymers with high FLN contents exhibit low $[\mathrm{n}]$ resulting in limited film-forming properties, while the [n] of PFPN $\left(\sim 0.38 \mathrm{dL} \mathrm{g}^{-1}\right)$ is still close to Olsson et al.'s PAPs $^{24}\left(\sim 0.2\right.$ to $\left.\sim 0.47 \mathrm{dL} \mathrm{g}^{-1}\right)$. PFAP copolymers with high $[\mathrm{n}]$ exhibit preferable film-forming properties.

Water sorption and transport behavior and gas permeability. Water management plays a crucial role in AEMFCs. Water is a reactant in the cathode and a product in the anode, and the amount of water generated in the anode is two times faster than the electrochemical consumption of water in the cathode (Fig. 2a). This is why it is easy to flood the anode, while the cathode is inclined to dry out. Different PFAP- $x$ polymers exhibit significantly different water uptakes (WUs) and swelling ratios (SRs) with different counterions (Fig. 2b, Supplementary Fig. 16a, b). PFTP-13 (WU: $~ 45 \%$, SR: 16\%) and PFTP-0 (WU: 55\%, SR: 24\%) membranes exhibited much lower WU and SR in liquid water at $30^{\circ} \mathrm{C}$ compared to PFBP-14 (WU: $\sim 300 \%$, SR: $\sim 100 \%$ ) and PFBP-0 (WU: $\sim 350 \%$, SR: $\sim 110 \%$ ) due to lower IEC values. Meanwhile, the PFTP-13 membrane with higher IEC displayed lower SR and enhanced dimensional stability compared to the PFTP-0 membrane due to the presence of rigid FLN groups.

Dynamic water vapor sorption (DVS) of PFAP- $x$ membranes is significantly lower than their liquid WU (in equilibrium) at different RHs (Fig. 2c). PFBP-14 and PFTP-13 films exhibited lower water vapor sorption than PFBP-0 and PFTP-0 films, respectively, which is consistent with liquid WU behavior. Notably, WU represents the water sorption capacity of AEIs or AEMs when liquid water is forming in AEMFCs, while it cannot represent the water transport behavior. Therefore, water diffusivity of AEIs at different RHs was automatically estimated by DVS, as shown in Supplementary Table 4. PFBP-14 and PFBP-0 AEMs with higher IEC values exhibited slightly higher water diffusivities than those of PFTP-13 and PFTP-0 AEMs. PFBP-14 and PFTP-13 AEMs also display higher water diffusivities than those of PFBP-0 and PFTP-0 AEMs, respectively, due to the existence of FLN blocks.

Currently, the water transport behavior can be referred to as water diffusion or water permeability related to $\mathrm{AEMs}^{41,42}$. Three small gas molecules $-\mathrm{H}_{2}, \mathrm{O}_{2}$, and water vapor-reach and participate in catalytic reactions, yet none of the current reports has accurately analyzed the water vapor permeability $\left(P_{\text {water }}\right)$ through AEMs or AEIs at different RHs. Similar to water diffusivity behavior, water vapor permeabilities of PFBP-14 and PFBP-0 are 62,398 Barrer (where 1 Barrer $=10^{-10} \mathrm{~cm}^{3}$ (STP) $\mathrm{cm} \mathrm{cm}^{-2} \mathrm{~s}^{-1} \mathrm{~cm} \mathrm{Hg}^{-1}$ ) and 58,921 Barrer at $85 \% \mathrm{RH}$, respectively, and those of PFTP-13 and PFTP-0 are 20,000-25,000 Barrer (Fig. 2d). Note that BP-containing copolymers (PFBP-0 and PFBP-14) showed high water vapor sorption and much higher $P_{\text {water }}$ compared to TP containing AEPs (PFTP-13 and PFTP-0). FLN-containing PFAP copolymers (PFBP-14 and PFTP-13) with lower water vapor sorption and liquid WU exhibited similar or even higher water vapor permeability than that of PAP AEPs (PFBP-0 and PFTP-0) due to the rigid FLN groups, the unique phase-separated morphology, and large water channels (Supplementary Fig. 17). The detailed discussion of membrane morphology and water channels are presented in Supplementary information.

On the other hand, the $\mathrm{H}_{2}$ and $\mathrm{O}_{2}$ permeabilities of AEPs were measured and recorded at different RHs using Barrer as a unit that is well-known in gas separation communities ${ }^{43}$ (Fig. 2e and Supplementary Fig. 16c, d). PFTP-13 and PFTP-0 exhibited much lower $\mathrm{H}_{2} \quad(\sim 10$ Barrer $)$ and $\mathrm{O}_{2} \quad(<0.5$ Barrer $)$ permeabilities compared to PAP-TP-85 $\left(\mathrm{H}_{2}: \sim 35 \text { Barrer }\right)^{17}$, commercial FAA-3$50\left(\mathrm{H}_{2}: \sim 15\right.$ Barrer), indicating that the PFTP-13 and PFTP-0 AEMs possess superior gas barrier properties.

Electrochemical and physical properties. FLN-based PFAP copolymers exhibited superior ion conductivity compared to PAP AEPs (Fig. 3a, b). Among these AEPs, PFTP-13 AEPs with the lowest swelling ratio displayed the highest ion conductivities of 208 and $77 \mathrm{mS} \mathrm{cm}^{-1}$ in $\mathrm{OH}^{-}$and $\mathrm{Cl}^{-}$forms, respectively, at $98^{\circ} \mathrm{C}$. An appropriate FLN segment incorporated into the PFAP backbone is beneficial for improving ion conductivity. Supplementary Fig. 17 shows that PFTP-13 and PFBP-14 AEPs possess preferable microphase separated morphologies and larger water channels compared to PFTP-0 and PFBP-0 AEPs, which improves their ion conductivity and water vapor permeability. The $\mathrm{CO}_{3}{ }^{2-}$ conductivities of PFTP-13 and PFBP-14 were over 65 $\mathrm{mS} \mathrm{cm}{ }^{-1}$ at $80^{\circ} \mathrm{C}$ (Supplementary Fig. 18), meaning that the PFTP-13 and PFBP-14 still possess high ion conductivity after carbonation ${ }^{13}$. Differential scanning calorimetry (DSC) analysis showed that excessive free water content $\left(N_{\text {free }}\right)$ in PAP AEPs did not enhance the ion conductivity (Supplementary Fig. 19 and Table 2), indicating that the ion conductivity of swollen PAP AEMs does not always match well with IEC, but is related to the morphology and water transport behavior ${ }^{17,31}$.

PFTP-13 exhibits high tensile strength (TS, 84.6 MPa), elongation at break (EB, 25.6\%), and Young's modulus (YM, $1580 \mathrm{MPa}$ ) among these AEPs, and it can be easily fabricated into thin membranes (7-20 $\mu \mathrm{m})$ (Fig. 3c-g and Supplementary Fig. 20). Supplementary Table 5 lists the mechanical properties of AEMs reported to date. The mechanical properties of the PFTP-13 AEMs without reinforcement are close to the best in current research. PFAP-13 AEMs possess high glass-transition temperatures $\left(T_{\mathrm{g}}\right)$ and an excellent storage modulus (SM) $\left(E^{\prime}\right)$ over $1500 \mathrm{MPa}$ at $80^{\circ} \mathrm{C}$ (Supplementary Figs. 21 and 22) that is the highest value so far in AEMs. This implies that PFTP-13 AEMs possess high rigidity and thermomechanical stability. Note that PFAP copolymers show two $T_{\mathrm{g}} \mathrm{s}$, which are due to the two different segments in the polymer backbone. In contrast, homopolymers such as PFTP0 and PFBP- 0 exhibit only one $T_{\mathrm{g}}$. On these grounds, the PFTP-13 copolymer with low SR, excellent dimensional stability, and high ion conductivity was chosen as representative AEMs, while PFBP14 with high ion conductivity, high water permeability (or water diffusivity), but limited dimensional stability was selected as representative AEIs in this work. 


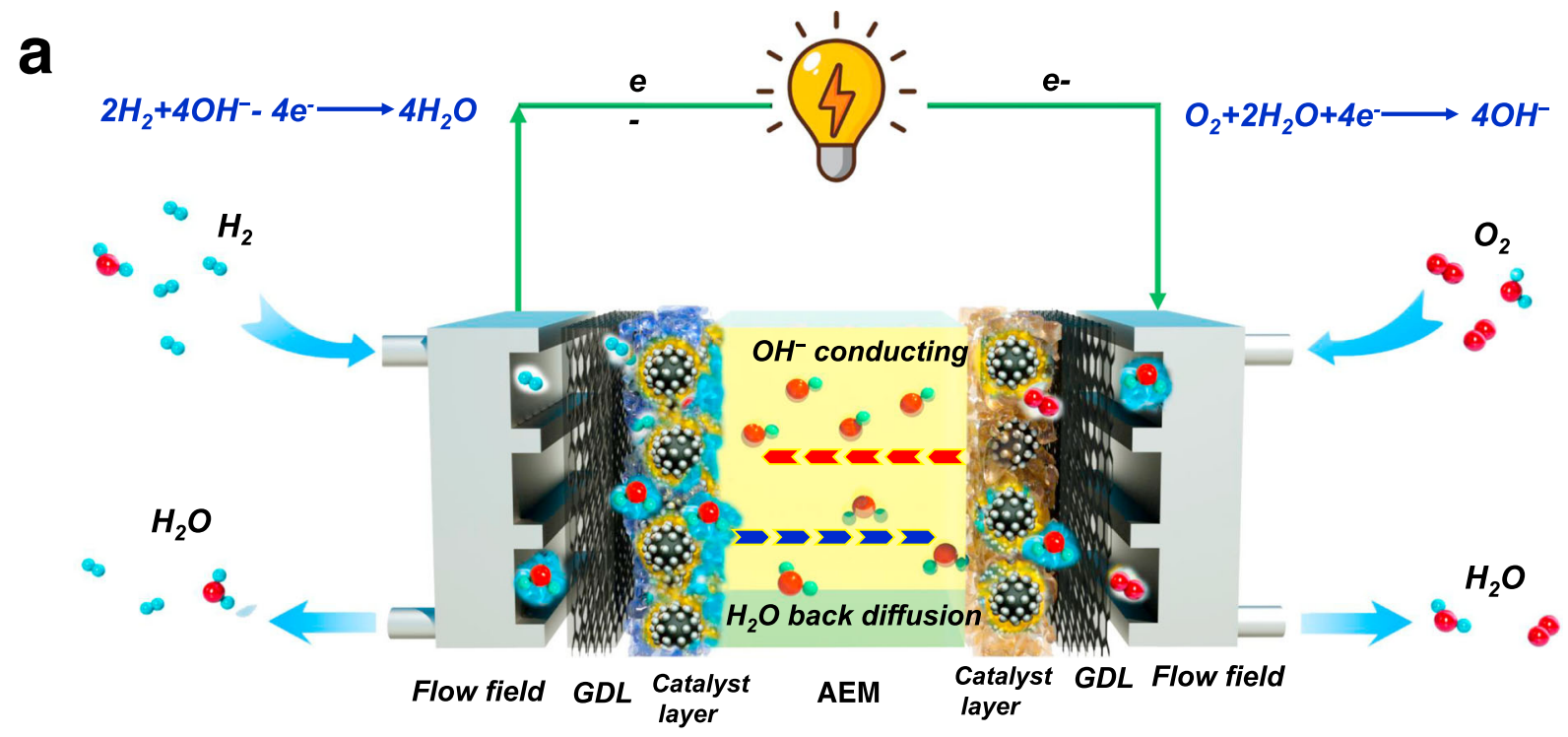

Anode
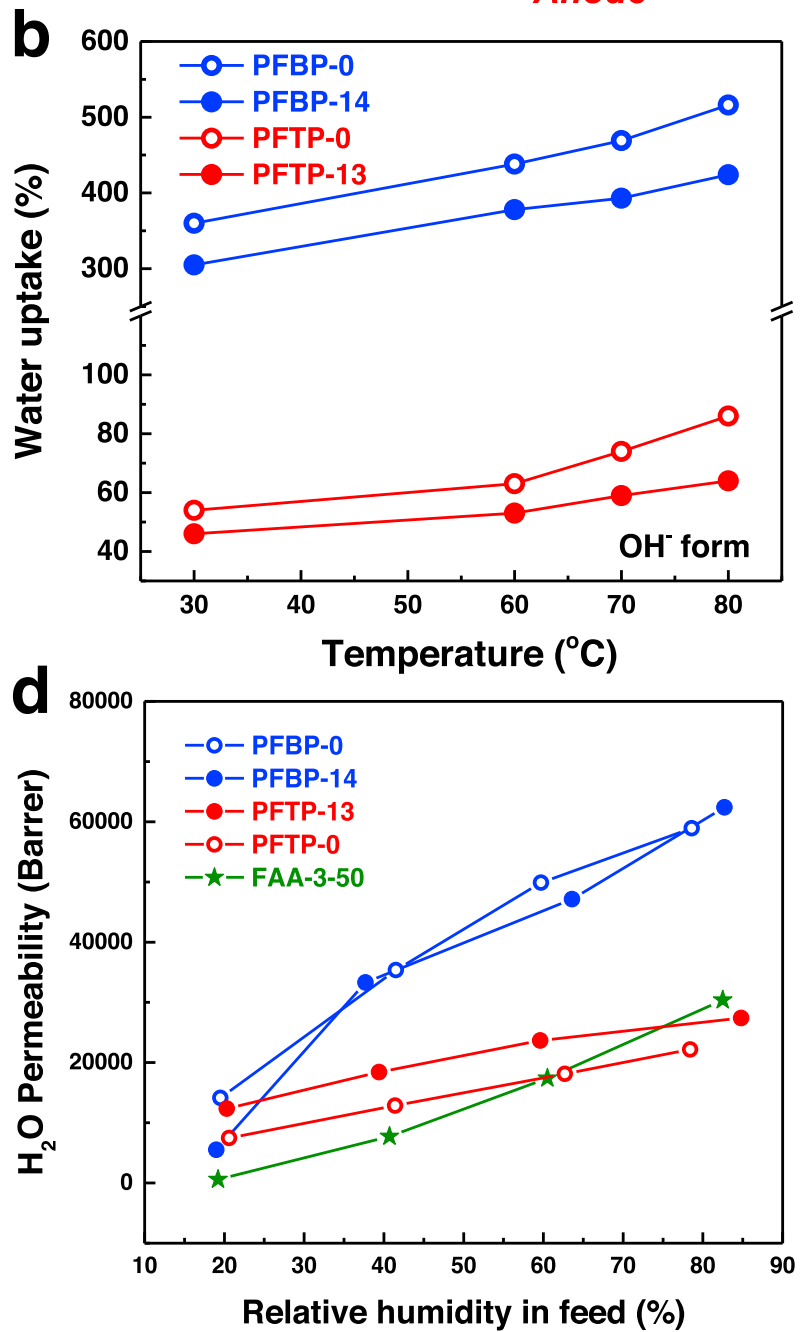

Cathode
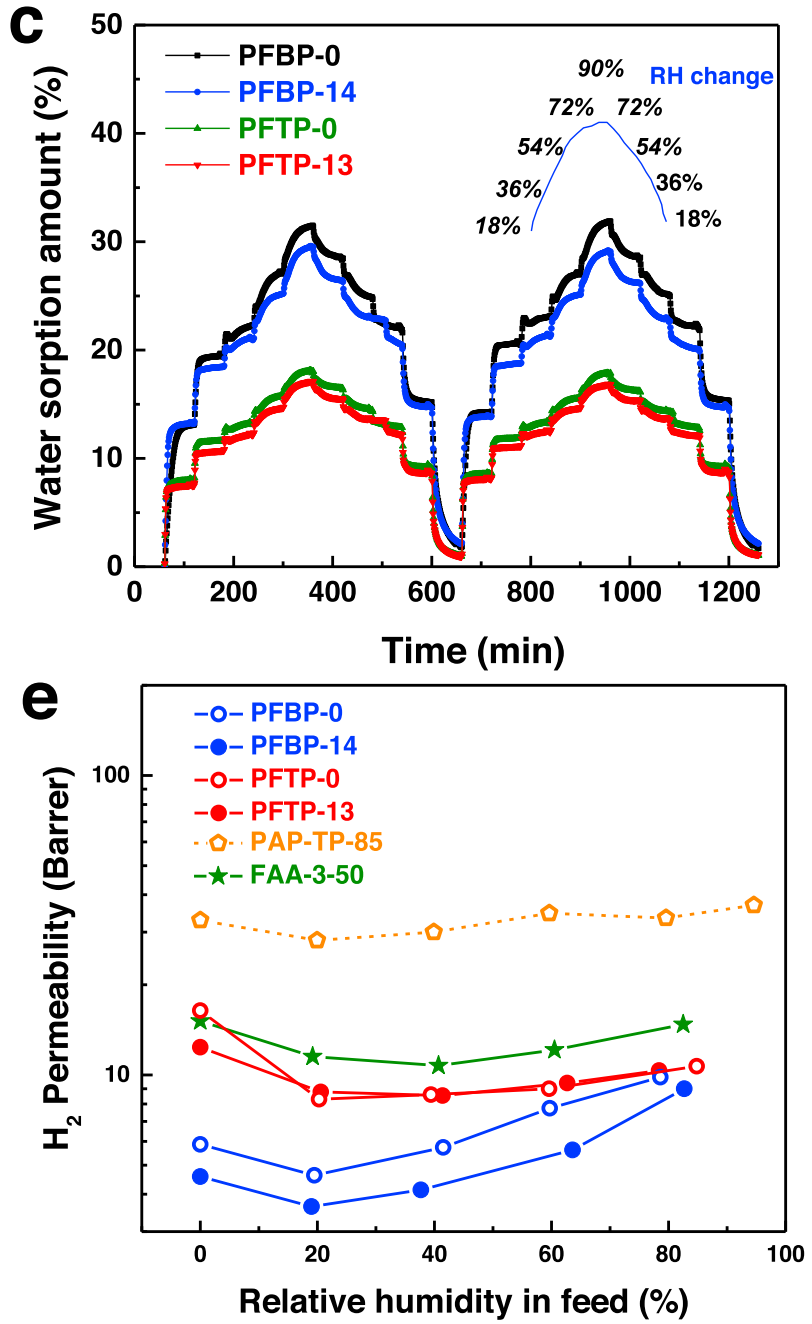

Fig. 2 Gas and water sorption and transport behavior. a Schematic diagram of the membrane electrode assembly (MEA) in AEMFCs emphasizing fuel gas and water transport. b The WU of PFBP-0, PFBP-14, PFTP-0, and PFTP-13 membranes in $\mathrm{OH}^{-}$form in liquid water. c Dynamic water vapor sorption behavior of PFBP-0, PFBP-14, PFTP-0, and PFTP-13 membranes at different RHs measured in a DVS instrument (RH changes between 18\%, 36\%, 54\%, $72 \%, 90 \%$ at a time interval of $60 \mathrm{~min}$ ) at $25^{\circ} \mathrm{C}$. RH is controlled to automatically increase in a DVS instrument at a given time interval. Two hydration-dehydration cycles were recorded. d Water vapor permeability, and e $\mathrm{H}_{2}$ permeability of different $\mathrm{AEPs}$ in $\mathrm{I}^{-}$form at $60^{\circ} \mathrm{C}$ under 2.2 bar unilateral backpressure. $\mathrm{H}_{2}$ permeability of reported PAP-TP-x ${ }^{17}$ is presented for comparison. 

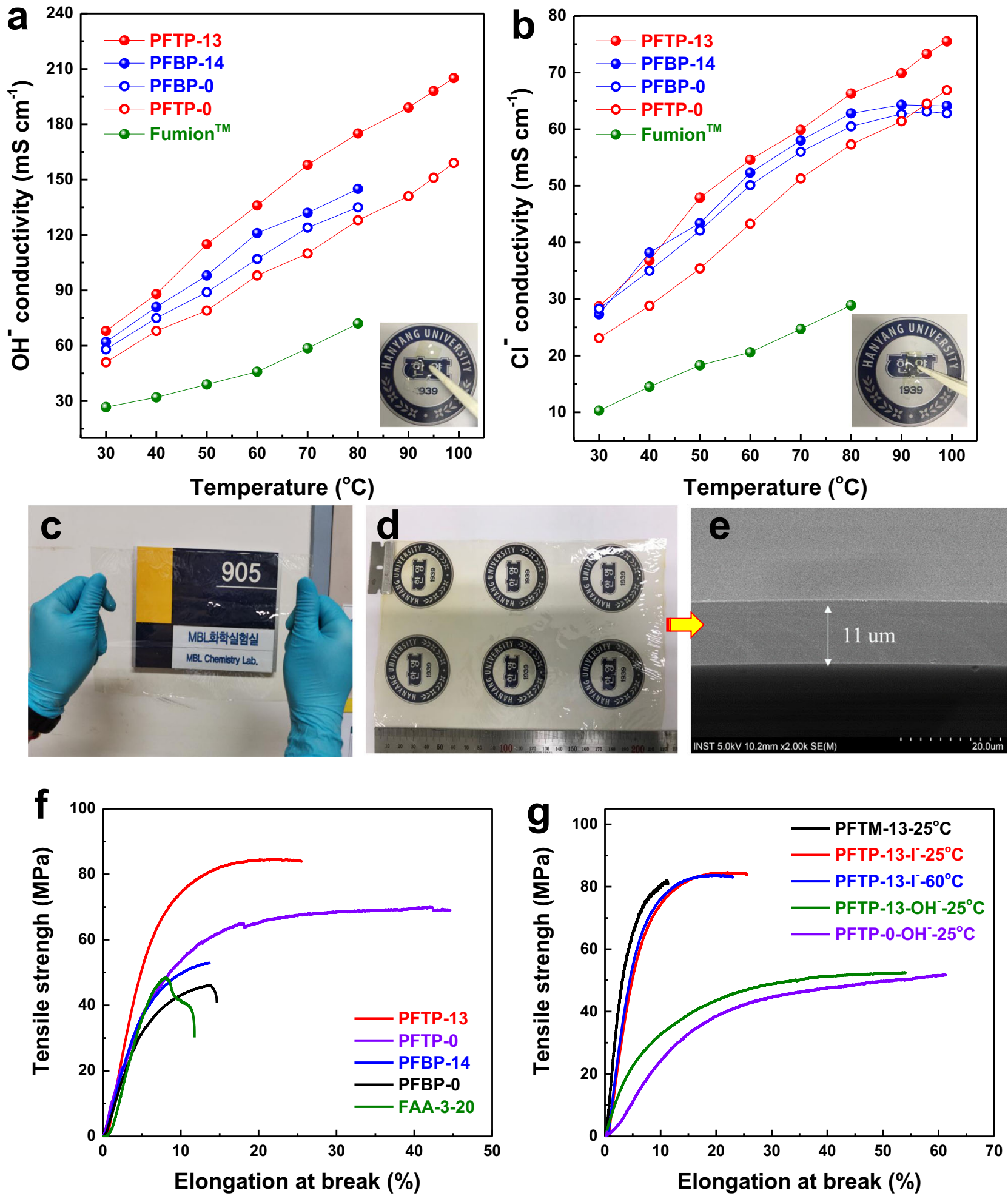

Fig. 3 Physical properties of AEMs. a $\mathrm{OH}^{-}$and $\mathbf{b} \mathrm{Cl}^{-}$conductivity of different AEMs as a function of temperature along with the picture of PFTP-13 membranes after testing at $98^{\circ} \mathrm{C}$. PFBP-14 and PFBP-O membranes showed poor dimensional stability at high temperatures, and thus it was difficult to measure their $\mathrm{OH}^{-}$conductivities over $90^{\circ} \mathrm{C}$. c, d A picture of transparent PFTP- 13 membranes $13.5 \times 22.5 \mathrm{~cm}$ in size. e SEM image of a cross-section of PFTP-13 membrane with a thickness of $\sim 15 \mu \mathrm{m}$. $\mathbf{f}$ The TS and EB of AEMs in I $^{-}$form and commercial FAA-3-20 membranes at room temperature. Compared to the present PFTP-0 AEMs (TS: 71 MPa, EB: 45.7\%, YM: 1.2 GPa) and reported PAP-TP-x AEMs (TS: 67 MPa and EB:117\%) ${ }^{17}$, PFTP-13 AEMs exhibit much higher TS and YM but lower EB, indicating that the PFTP-13 AEMs have a higher deformation resistance. $\mathbf{g}$ The tensile strength and elongation at break of PFTP-13 and PFTP-0 membranes at different temperatures and types. PFTM-13 is PFTP-14 before quaternization, whereas PFTP-13-I- and PFTP$13-\mathrm{OH}^{-}$are in $\mathrm{I}^{-}$and $\mathrm{OH}^{-}$forms, respectively. PFTP-13 AEMs maintain their mechanical properties at $60^{\circ} \mathrm{C}$. Compared to Peng et al. 's PFTP-0 AEMs 36 (TS: $35 \mathrm{MPa}$ and EB: 40\%), the present PFTP-13 and PFTP-O AEMs (TS: > $50 \mathrm{MPa}$ and EB: $\sim 60 \%$ ) in $\mathrm{OH}^{-}$form exhibit much higher mechanical properties due to their higher intrinsic viscosity. 
AEMFC performance. The effect of water behavior of AEIs on AEMFC performance was systematically investigated at different RHs based on the commercial FAA-3-20 and PFTP-13 AEMs with TKK Pt/C. At high anode/cathode (A/C) RHs (90\%/100\%) and low current density $\left(<2.5 \mathrm{~A} \mathrm{~cm}^{-2}\right)$, Supplementary Fig. 23a showed that PFTP-13 (WU: $~ 50 \%$ ) and PFBP-14 (WU: 300\%) ionomers exhibited similar PPDs at $65^{\circ} \mathrm{C}$ based on the commercial FAA-3-20 membrane, while those of FLN-based ionomers show higher PPDs than PFBP-0 (WU: 350\%) and PFTP-0 (WU: 55\%) ionomers due to the lower phenyl adsorption (Supplementary Fig. 23b) and higher ion conductivity. On the other hand, at high $\mathrm{RH}$ and moderate current density $\left(\sim 3.5 \mathrm{~A} \mathrm{~cm}^{-2}\right)$ (Fig. $\left.4 \mathrm{a}\right)$ or at low RHs $(50 \% / 80 \%)$ and high current density $\left(>5 \mathrm{~A} \mathrm{~cm}^{-2}\right)$ (Fig. 4b), PFBP$14\left(1.42 \mathrm{~W} \mathrm{~cm}^{-2}\right)$ and PFBP-0 $\left(1.19 \mathrm{~W} \mathrm{~cm}^{-2}\right)$ exhibited higher PPDs than PFTP-13 $\left(1.06 \mathrm{~W} \mathrm{~cm}^{-2}\right)$ and PFTP-0 $\left(0.98 \mathrm{~W} \mathrm{~cm}^{-2}\right)$ ionomers due to lower phenyl adsorption and higher $P_{\text {water }}$ (or high water diffusivity). According to Matanovic et al.'s discovery ${ }^{37,38}$, poly(biphenyl)-based ionomers showed higher PPDs than poly (terphenyl)-based ionomers due to lower phenyl adsorption, which is basically matching with our results. Moreover, high $P_{\text {water }}$ of PFBP-14 AEIs with moderate WU contributed to rapidly discharging the generated water in the anode which improved the water back diffusion or to maintaining the water content at low $\mathrm{RH}$ conditions. PFBP-14 ionomers ( $300 \% \mathrm{WU}$ at room temperature) showed much lower WU compared to the state-of-the-art PF ionomers $^{34}$ (side-chain-type FLN-100, WU $>2000 \%$ at room temperature) at similar IECs $\left(\sim 3.45 \mathrm{mmol} \mathrm{g}^{-1}\right)$. Therefore, PFBP-14 ionomers with moderate $\mathrm{WU}$ did not raise the anode flooding issues in the present AEMFCs. On the contrary, PFTP-13 ionomers with low WU and high conductivity showed limited AEMFC performance at low $\mathrm{RH}$ due to relatively low $P_{\text {water }}$. Meanwhile, AEMs also require reasonable water permeability. Note that PFTP-13 AEMs display higher PPDs than the commercial FAA series ${ }^{14}$ and PFTP-0 AEMs due to higher ion conductivity, mechanical properties, and $P_{\text {water }}$ (or water diffusivity) (Supplementary Fig. 24).

Unfortunately, PFPN-100 and PFPN-85 AEIs with low phenyl adsorption and high rigidity (Supplementary Figs. 13 and 14) possess insufficient intrinsic viscosity (or molecular weight), which cannot tightly hold on catalyst particles, resulting in severe catalyst detachment from catalyst-coated membrane (CCM) during ionexchange process. Therefore, AEMFC performance of PFPN- $x$ ionomers $\left(0.3-0.7 \mathrm{~W} \mathrm{~cm}^{-2}\right)$ is limited. Figure $4 \mathrm{c}$ shows that the PPDs of AEMFCs are significantly impacted by the [n] of PFBP- $x$ AEIs, and the detachment issue has been found when the [n] is lower than $1 \mathrm{dL} \mathrm{g}^{-1}$ along with PPD decrease. Development of PFPN- $x$ and PFBP- $x$ ionomers with reasonable molecular weight will be our future work. These discoveries provide a clear information for the PAP family to rationally design AEIs with sufficient molecular weight. PFBP- $x$ AEIs containing 14-30\% FLNs displayed the highest PPDs $\left(1.52-1.64 \mathrm{~W} \mathrm{~cm}^{-2}\right)$ due to the reasonable [n] and high $P_{\text {water. }}$.

Based on PFBP-14 AEIs, PFTP-13 AEMs, and 75\%/100\% A/C $\mathrm{RH}$, the PPDs of AEMFCs reached $1.67 \mathrm{~W} \mathrm{~cm}^{-2}(0 / 0$ bar back pressure) and $2.34 \mathrm{~W} \mathrm{~cm}^{-2}(1.3 / 1.3$ bar back pressure $)$ at $80^{\circ} \mathrm{C}$ based on $\mathrm{Pt}-\mathrm{Ru} / \mathrm{C}$ anode (Fig. $4 \mathrm{~d}$ ). A small applied back pressure (0.5/0.5 bar) shows significant effect on the cell performance due to the higher electrode reactions and optimizing water transport that decreases the mass transport resistance (Fig. $4 \mathrm{~d}$ and Supplementary Fig. 24b). Under $\mathrm{H}_{2}$-air $\left(\mathrm{CO}_{2}\right.$ free $)$ conditions, the present AEMFCs reached PPDs of 1.25 and $1.01 \mathrm{~W} \mathrm{~cm}^{-2}$ with $0.42 \mathrm{mg} \mathrm{cm}^{-2} \mathrm{Pt}-\mathrm{Ru} / \mathrm{C}$ anode and $0.33 \mathrm{mg} \mathrm{cm}^{-2} \mathrm{Pt} / \mathrm{C}$ anode, respectively (Fig. 4e). Moreover, after replacing the expensive $\mathrm{Pt} / \mathrm{C}$ cathode with a home-made cobalt catalyst $\left(0.6 \mathrm{mg} \mathrm{cm}^{-2} \mathrm{Co@C/C}\right.$, $40 \mathrm{wt} \% \mathrm{Co})$, the PFAP-based AEMFCs still reached an impressive $\mathrm{PPD}$ of $0.891 \mathrm{~W} \mathrm{~cm}^{-2}$ at $80^{\circ} \mathrm{C}$ with a low back pressure (Fig. $4 \mathrm{f}$ ).
Optimized AEMFCs based on the Co@C/C cathode will be presented in our following paper.

Supplementary Table 6 summarizes all the fuel cell performances with low catalyst loadings conducted in this work, and these are compared with those in the literature. Currently, the state-of-the-art PTFE-reinforced PNB (GT- $x$ series: $3.2 \mathrm{~W} \mathrm{~cm}^{-2}$ in $\mathrm{H}_{2}-\mathrm{O}_{2}$ and $1.75 \mathrm{~W} \mathrm{~cm}^{-2}$ in $\mathrm{H}_{2}$-air without back pressure ${ }^{2} ; 3.5 \mathrm{~W} \mathrm{~cm}^{-2}$ in $\mathrm{H}_{2}-\mathrm{O}_{2}$ and $1.25 \mathrm{~W} \mathrm{~cm}$ -2 in $\mathrm{H}_{2}$-air with $0.5 / 1.0$ bar back pressure ${ }^{31}$ ) and BTMAHDPE $\left(2.35-2.5 \mathrm{~W} \mathrm{~cm}^{-2}\right.$ in $\mathrm{H}_{2}-\mathrm{O}_{2}$ and $1.06 \mathrm{~W} \mathrm{~cm}^{-2}$ in $\mathrm{H}_{2}$-air without back pressure) ${ }^{3,29}$ AEMs lead the current AEMFCs, while our present AEMFCs display comparable power density $\left(2.34 \mathrm{~W} \mathrm{~cm}^{-2}\right.$ in $\mathrm{H}_{2}-\mathrm{O}_{2}$ and $1.25 \mathrm{~W} \mathrm{~cm}^{-2}$ in $\mathrm{H}_{2}$-air with $1.3 / 1.3$ bar back pressure). On the other hand, compared to the state-of-the-art polyaromatics-based AEMFCs $\left(<2.08 \mathrm{~W} \mathrm{~cm}^{-2}\right.$ in $\mathrm{H}_{2}-\mathrm{O}_{2}$ with $2.0 / 2.0$ bar back pressure $)^{17,32,34}$, our present AEMFCs showed higher PPDs. Note that GT- $x$ series and BTMA-HDPE-based AEMFCs employed a high $\mathrm{Pt}-\mathrm{Ru} / \mathrm{C}$ loading of $0.7 \mathrm{mg} \mathrm{cm}^{-2}$, while the present PFAP-based cells exhibited high performance with a low PGM loading of $0.33-0.42 \mathrm{mg} \mathrm{cm}^{-2} 44,45$.

Figure 5 summarizes the $\mathrm{PPD}$ and $\mathrm{OH}^{-}$conductivities of representative AEIs in current research. Compared to side-chaintype PF AEIs and poly(terphenylene) AEMs, PFBP-14 AEIs and PFTP-13 AEMs showed higher ion conductivity and PPDs. Although BTMA-ETFE ionomers displayed the slightly higher PPDs, the alkaline stability issues associated with the BTMAETFE still have not been well addressed. Our present ion conductivity and PPDs are the topmost values to date, compared to polyfluorene (PF), polyphenylene (PP) and PAP AEIs. This indicates that PFAP AEPs are good candidates for AEI and AEM applications.

Ex-situ and in-situ durability. Based on the high-throughput testing of current AEMs by the National Renewable Energy Laboratory (NREL) ${ }^{8}$, most AEMs show severe deformation of the membranes and even exhibit fracture along with color changes (in some cases) after testing in $1 \mathrm{M} \mathrm{KOH}$ at $80^{\circ} \mathrm{C}$ for $1000 \mathrm{~h}$. PFTP-13 AEMs are stable in $1 \mathrm{M} \mathrm{NaOH}$ at $80^{\circ} \mathrm{C}$ for $2000 \mathrm{~h}$ and maintain transparency and mechanical toughness after ex-situ durability testing (Fig. 6a and Supplementary Fig. 25). 20\% loss in ion conductivity was found in PFTP-13 after alkaline treatment in $5 \mathrm{M} \mathrm{NaOH}$ at $80^{\circ} \mathrm{C}$ for $2000 \mathrm{~h}$. Meanwhile, PFTP-13 AEMs were unstable under $10 \mathrm{M} \mathrm{NaOH}$ conditions, and significant degradation in chemical structure and mechanical loss were detected after $168 \mathrm{~h}$ (Supplementary Figs. 26-28).

As presented in Fig. 6b, in-situ durability testing of AEMFCs demonstrated that the present AEMFCs based on PFBP-14 ionomers and a PFTP-13 membrane can be operated stably under a $0.2 \mathrm{~A} \mathrm{~cm}^{-2}$ current density at $70{ }^{\circ} \mathrm{C}$ in $\mathrm{H}_{2}-\mathrm{O}_{2}$ with a low $\mathrm{A} / \mathrm{C}$ flow rate, and only $3.68 \%$ voltage decay $\left(\sim 130 \mu \mathrm{Vh}^{-1}\right)$ was observed after $\sim 200 \mathrm{~h}$. On the other hand, the commercial FAA membranes and ionomer-based AEMFCs showed significant voltage loss (over $40 \%$ voltage decay) within $48 \mathrm{~h}$ (Supplementary Fig. 29). Peng et al. reported $120 \mathrm{~h}$ in-situ durability at a $0.2 \mathrm{~A} \mathrm{~cm}^{-2}$ current density $\left(\sim 10 \%\right.$ voltage decay, $\left.\sim 800 \mu \mathrm{Vh}^{-1}\right)$ at $80^{\circ} \mathrm{C}$ based on PFTP-0 $\mathrm{AEMs}^{36}$. Yan and coworkers ${ }^{17}$ presented $300 \mathrm{~h}$ in-situ durability $\left(\sim 11.5 \%\right.$ voltage decay at $\left.250 \mathrm{~h}, \sim 300 \mu \mathrm{V} \mathrm{h}^{-1}\right)$ at a $0.5 \mathrm{~A} \mathrm{~cm}^{-2}$ current density at $95^{\circ} \mathrm{C}$ based on PAP-TP- $x$ AEMs. Very recently, a few state-of-the-art AEMFCs ${ }^{3,46}$ reported $\sim 1000 \mathrm{~h}$ in-situ durability (voltage decay $32-350 \mu \mathrm{Vh}^{-1}$ ), and GT- $x$-based AEMFCs ${ }^{2}$ could even obtain $2000 \mathrm{~h}$ in-situ durability (only $3.65 \%$ voltage decay, $\sim 15 \mathrm{\mu V} \mathrm{h}^{-1}$ ) under a $0.6 \mathrm{~A} \mathrm{~cm}^{-2}$ current density at $75^{\circ} \mathrm{C}$. 

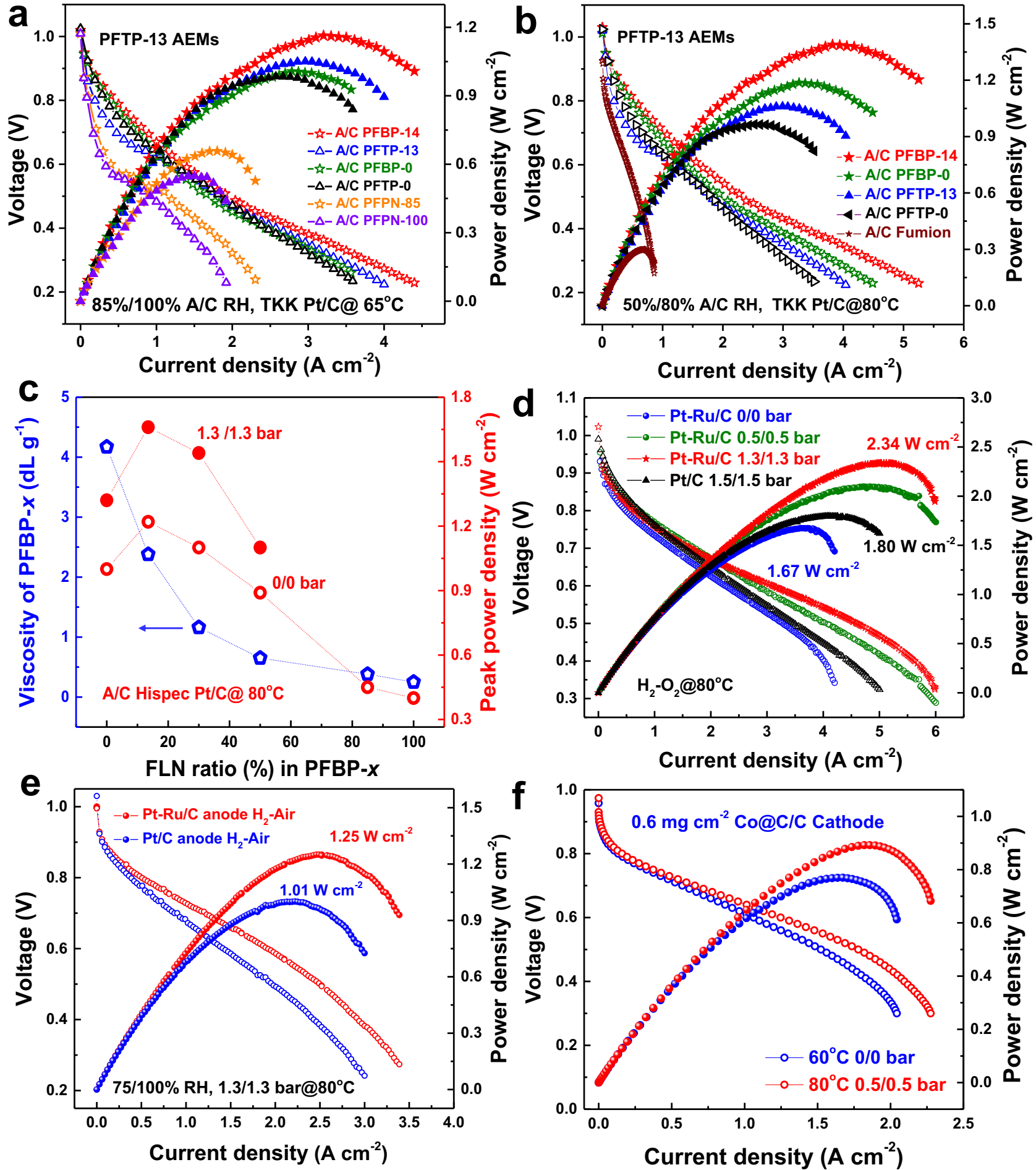

Fig. 4 Fuel cell performance. a The power density of AEMFCs with different AEls and PFTP-13 AEMs $(25 \pm 3 \mu \mathrm{m})$ based on $\mathrm{A} / \mathrm{C}$ TKK Pt/C catalysts ( $0.33 \mathrm{mg} \mathrm{cm}^{-2}$ ): $1000 / 1000 \mathrm{~mL} \mathrm{~min}^{-1} \mathrm{H}_{2}-\mathrm{O}_{2}$ flow rate, $65^{\circ} \mathrm{C}, 85 \% / 100 \% \mathrm{~A} / \mathrm{C} \mathrm{RH}$, and $0.5 / 0.5$ bar back pressure. b the power density of $\mathrm{AEMFCs}$ with different AEls and PFTP-13 AEMs $(25 \pm 3 \mu \mathrm{m})$ based on A/C TKK Pt/C catalysts $\left(0.33 \mathrm{mg} \mathrm{cm}^{-2}\right): 80^{\circ} \mathrm{C}, 50 \% / 80 \% \mathrm{~A} / \mathrm{C} \mathrm{RH}$, and $1.3 / 1.3$ bar backpressure. c The relationship between the PPDs and the intrinsic viscosity of PFBP-x AEls: PFTP-13 AEMs $(25 \pm 3 \mu \mathrm{m}), \mathrm{H}_{2}-\mathrm{O}_{2}, \mathrm{~A} / \mathrm{C} \mathrm{Hispec} \mathrm{Pt/C}$ catalysts $\left(0.33 \mathrm{mg} \mathrm{cm}^{-2}\right), 80^{\circ} \mathrm{C}$, the $\mathrm{A} / \mathrm{C}$ flow rate of $1000 / 1000 \mathrm{~mL} \mathrm{~min}^{-1}, 75 \% / 100 \% \mathrm{~A} / \mathrm{C} \mathrm{RH}$. Hollow circle symbols are PPDs without back pressure, while filled circle symbols are PPDs with 1.3/1.3 bar back pressure. $\mathbf{d}$ The power density of AEMFCs based on Pt-Ru/C anode with backpressure: PFBP-14 AEls and PFTP-13 AEMs $(20 \pm 3 \mu \mathrm{m}), 80^{\circ} \mathrm{C}, 75 \% / 100 \% \mathrm{~A} / \mathrm{C} \mathrm{RH}, 1000 / 1000 \mathrm{~mL} \mathrm{~min}^{-1} \mathrm{H}_{2}-\mathrm{O}_{2}$ flow rate, different back pressures, Pt-Ru/C anode $\left(0.42 \mathrm{mg} \mathrm{cm}^{-2}\right)$, Hispec Pt/C cathode $\left(0.33 \mathrm{mg} \mathrm{cm}^{-2}\right)$. A/C Hispec Pt/C $\left(0.33 \mathrm{mg} \mathrm{cm}^{-2}\right)$ for comparison. e the power density of AEMFCs in $\mathrm{H}_{2}$-air $\left(\mathrm{CO}_{2}\right.$ free) with different anode catalysts: PFBP-14 AEls and PFTP-13 AEMs $(20 \pm 3 \mu \mathrm{m}), 80^{\circ} \mathrm{C}, 75 \% / 100 \% \mathrm{~A} / \mathrm{C} \mathrm{RH}, 1000 / 2000 \mathrm{~mL} \mathrm{~min}^{-1} \mathrm{flow}$ rate, $1.3 / 1.3 \mathrm{bar}$ $\mathrm{A} / \mathrm{C}$ backpressure, $0.33 \mathrm{mg} \mathrm{cm}^{-2} \mathrm{~A} / \mathrm{C}$ catalyst loading. f PFAP-based AEMFCs with $0.6 \mathrm{mg} \mathrm{cm}^{-2}$ loading of Co@C/C cathode and Pt-Ru/C anode with $1000 / 1000 \mathrm{~mL} \mathrm{~min}^{-1} \mathrm{H}_{2}-\mathrm{O}_{2}$ flow rate at 60 and $80^{\circ} \mathrm{C}$. PPDs reached $0.769 \mathrm{~cm}^{-2}$ and $0.891 \mathrm{~W} \mathrm{~cm}^{-2}$ at $60^{\circ} \mathrm{C}$ without backpressure and at $80^{\circ} \mathrm{C}$ with $0.5 / 0.5$ bar backpressure, respectively. 


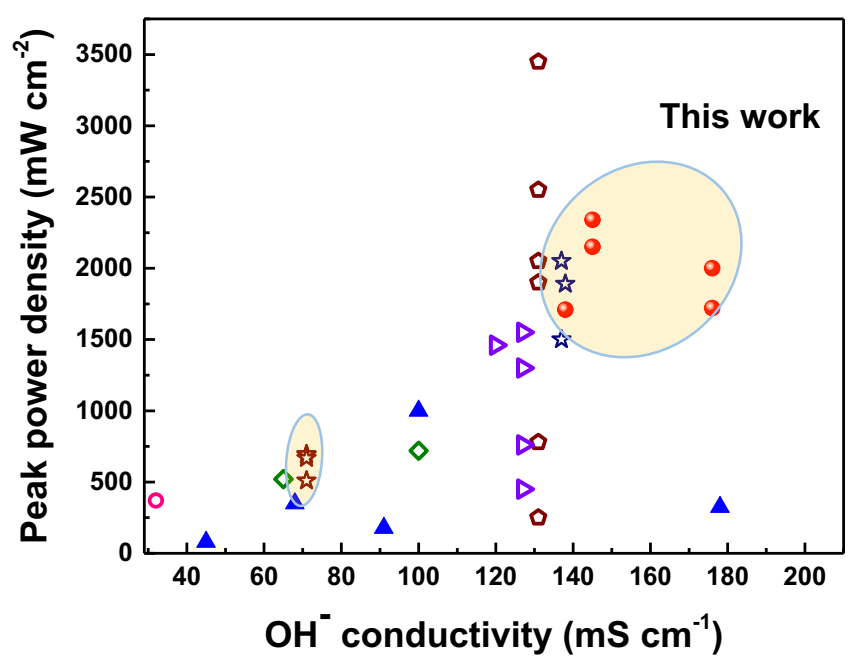

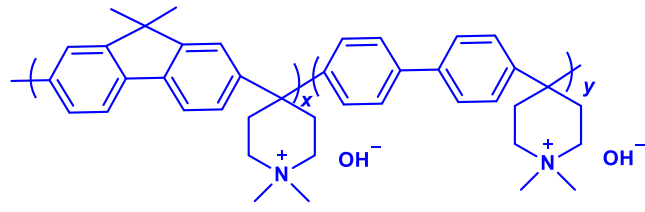

High IEC and high $\mathrm{P}_{\text {water }}$ AEls for
low and high RH

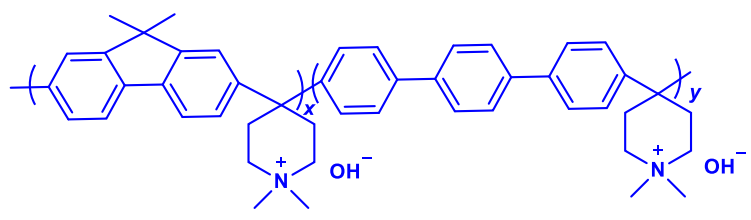

High IEC, low WU and high $\sigma$
AEls and AEMs for high RH

Fig. 5 Comparison of representative AEls in current research in regard to $\mathbf{O H}^{-}$conductivity and PPDs at $\mathbf{8 0}{ }^{\circ} \mathbf{C}$. $P F A P$ (red $c y c l e$ ) and $F A A F u m i o n$ ionomers (brown star) in this work. PSF/PPO ionomers (blue triangle symbols): BMTA-polysulfone ${ }^{49}$, BTMA-PPO ${ }^{11}$, DMP-PPO, ASU-PPO26, and multication side chain PPO50. PBI ionomers (pink circle symbols): HMT-PBI26; BTMA-ETFE ionomers (brown pentagon symbols) ${ }^{12,15,29-31,33}$. BTMA-SEBS

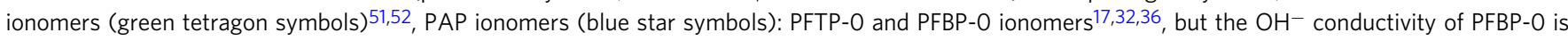
currently missing. PF/PP ionomers (purple triangle symbols): side-chain polyfluorene and polyphenylene ${ }^{34,37 .}$
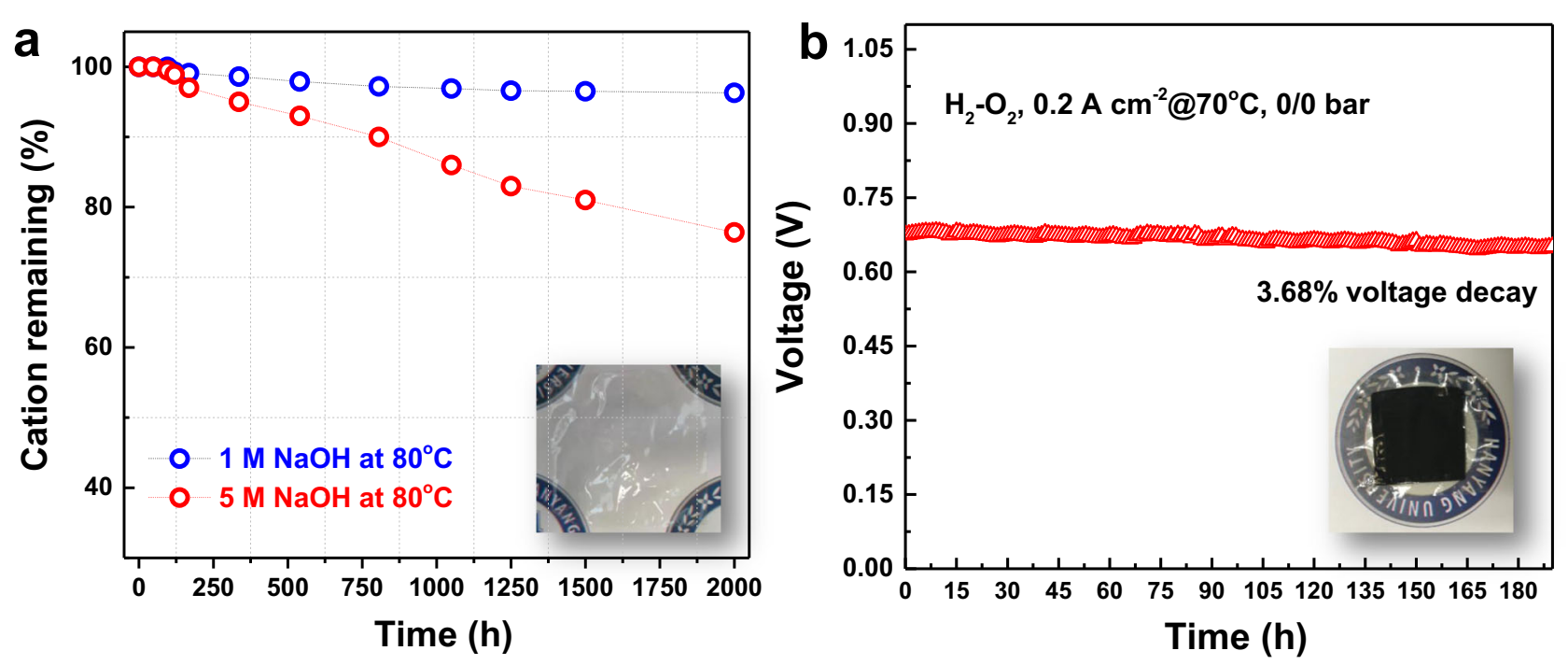

Fig. 6 Ex-situ and in-situ durability. a Remaining cations (\%) of PFTP-13 AEMs at different concentrations of $\mathrm{NaOH}$ (1 and $5 \mathrm{M}$ ) at $80{ }^{\circ} \mathrm{C}$ for $2000 \mathrm{~h}$ detected by ${ }^{1} \mathrm{H}$ NMR, along with the picture of membrane after alkaline treatment in $1 \mathrm{M} \mathrm{NaOH}$ for $2000 \mathrm{~h}$. $3 \%$ and $22 \%$ loss in ion conducting groups (piperidinium) was detected by ${ }^{1} \mathrm{H}$ NMR testing after immersion in those alkaline solutions. $\mathbf{b}$ In-situ durability of $\mathrm{H}_{2}-\mathrm{O}_{2}$ AEMFCs based on $\mathrm{PFBP}-14 \mathrm{AEI}_{\mathrm{s}}$ and PFTP-13 AEMs testing at a $0.2 \mathrm{~A} \mathrm{~cm}^{-2}$ current density at $70{ }^{\circ} \mathrm{C}$ with a $200 / 200 \mathrm{~mL} \mathrm{~min}^{-1} \mathrm{~A} / \mathrm{C} \mathrm{flow}$ rate and $90 / 100 \% \mathrm{~A} / \mathrm{C} \mathrm{RH}$, along with the picture of CCM after in-situ durability testing.

\section{Discussion}

In summary, a series of high-performance PFAP- $x$ AEIs and AEMs have been developed in this work. PFTP-13 AEMs simultaneously possessed $>80 \mathrm{MPa}$ TS and $\sim 1500 \mathrm{MPa}$ SM, excellent dimensional stability, and over $200 \mathrm{mS} \mathrm{cm}{ }^{-1} \mathrm{OH}^{-}$ conductivity at $98^{\circ} \mathrm{C}$. AEMFC performance demonstrated that PFBP-14 AEIs with suitable water vapor permeability exhibited superior PPDs at moderate or low RHs, which improved the mass transport efficiency and water diffusion in AEMFCs. The present AEMFCs reach PPDs of 2.34 and $1.25 \mathrm{~W} \mathrm{~cm}^{-2}$ in $\mathrm{H}_{2}-\mathrm{O}_{2}$ and $\mathrm{H}_{2}$-air, respectively. In-situ durability demonstrated that the present AEMFCs can be operated stably under a $0.2 \mathrm{~A} \mathrm{~cm}^{-2}$ current density for $\sim 200 \mathrm{~h}$ at $70{ }^{\circ} \mathrm{C}$. All these results indicate that these rigid PFAP AEMs and AEIs are promising candidates for AEMFCs.

\section{Methods}

Synthesis of poly(fluorene-co-aryl methylpiperidine) (PFAM-x). A typical synthesis procedure of $\mathrm{PF}_{0.13} \mathrm{~T}_{0.87} \mathrm{M}$ (or PFTM-13) is as follows: terphenyl $(8.28 \mathrm{~g}$, $36 \mathrm{mmol}), 9,9^{\prime}$-dimethylfluorene ( $\left.0.777 \mathrm{~g}, 4 \mathrm{mmol}\right)$, and 1-methyl-4-piperidone $(5.12 \mathrm{~mL}, 44 \mathrm{mmol})$ were added into a three-neck reactor, and then dichloromethane $\left(\mathrm{CH}_{2} \mathrm{Cl}_{2}, 32 \mathrm{~mL}\right)$ was added to dissolve the monomers with mechanical stirring, followed by $\mathrm{N}_{2}$ purge for $10 \mathrm{~min}$. After the temperature of the solution was cooled to $-3^{\circ} \mathrm{C}$ by a chiller, trifluoroacetic acid (TFA, $4.8 \mathrm{~mL}$ ) and trifluoromethanesulfonic acid (TFSA, $32 \mathrm{~mL}$ ) were slowly added into the above solution. The color of the above solution immediately became dark red after adding TFSA. The reaction was kept at $-3^{\circ} \mathrm{C}$ by continuous mechanical stirring at $\sim 10 \%$ 
$\mathrm{RH}$ for 7-12 $\mathrm{h}$ depending on the viscosity of the solution. Subsequently, a very viscous polymer solution with a black-red color was carefully poured into a $1 \mathrm{M}$ $\mathrm{NaOH}$ solution to produce white and stringy polymers. The polymer was smashed by a blender, and carefully washed several times with DI water until the $\mathrm{pH}$ was neutral. Finally, the polymer was dried in a vacuum oven at $80^{\circ} \mathrm{C}$ to obtain a pale yellow PFTM-13. Yield: >95\%. ${ }^{1} \mathrm{H}$ NMR (600 MHz, DMSO, $\left.\delta\right): 7.21-7.70 \mathrm{ppm}$ $\left(\mathrm{H}_{\mathrm{e}-\mathrm{h}}\right), 3.49 \mathrm{ppm}\left(\mathrm{H}_{\mathrm{a}}\right), 3.15 \mathrm{ppm}\left(\mathrm{H}_{\mathrm{a}^{\prime}}\right), 2.83 \mathrm{ppm}\left(\mathrm{H}_{\mathrm{b}}\right), 2.75 \mathrm{ppm}\left(\mathrm{H}_{\mathrm{c}}\right), 2.31 \mathrm{ppm}$ $\left(\mathrm{H}_{\mathrm{b}^{\prime}}\right)$, and $1.32 \mathrm{ppm}\left(\mathrm{H}_{\mathrm{d}}\right)$ (Supplementary Fig. 1a)

A typical synthesis procedure of $\mathrm{PF}_{0.14} \mathrm{~B}_{0.86} \mathrm{M}$ (or PFBM-14) is as follows. Biphenyl (4.158 g, $27 \mathrm{mmol}), 9,9^{\prime}$-dimethylfluorene $(0.5828 \mathrm{~g}, 3 \mathrm{mmol}), 1$-methyl4-piperidone (3.838 mL, $33 \mathrm{mmol})$, and $\mathrm{CH}_{2} \mathrm{Cl}_{2}(24 \mathrm{~mL})$ were added into a threeneck reactor with mechanical stirring. After the temperature of solution was cooled to $-3{ }^{\circ} \mathrm{C}$, TFA $(3.6 \mathrm{~mL})$ and TFSA $(24 \mathrm{~mL})$ were slowly added into the above solution. The color of the above solution immediately became dark red after adding TFSA. The reaction was kept at $-3{ }^{\circ} \mathrm{C}$ by continuous mechanical stirring at $\sim 10 \%$ $\mathrm{RH}$ for $4-6 \mathrm{~h}$ depending on the viscosity of the solution. Subsequently, a viscous and dark red polymer solution was carefully precipitated in a $1 \mathrm{M} \mathrm{NaOH}$ solution. The polymer was carefully washed in DI water three times until the $\mathrm{pH}$ became neutral. Finally, the polymer was dried in a vacuum oven at $80^{\circ} \mathrm{C}$ to obtain a pale yellow PFBM-14. Yield: $>95 \% .{ }^{1} \mathrm{H}$ NMR $(600 \mathrm{MHz}, \mathrm{DMSO}, \delta): 7.29-7.70 \mathrm{ppm}$ $\left(\mathrm{H}_{\mathrm{e}-\mathrm{h}}\right), 3.50 \mathrm{ppm}\left(\mathrm{H}_{\mathrm{a}}\right), 3.17 \mathrm{ppm}\left(\mathrm{H}_{\mathrm{a}^{\prime}}\right), 2.83 \mathrm{ppm}\left(\mathrm{H}_{\mathrm{b}}\right), 2.75 \mathrm{ppm}\left(\mathrm{H}_{\mathrm{c}}\right), 2.29 \mathrm{ppm}$ $\left(\mathrm{H}_{\mathrm{b}^{\prime}}\right)$, and $1.32 \mathrm{ppm}\left(\mathrm{H}_{\mathrm{d}}\right)$ (Supplementary Fig. 2).

Synthesis of PFAP-x copolymers. A typical synthesis procedure of $\mathrm{PF}_{0.13} \mathrm{~T}_{0.87} \mathrm{P}$ (or PFTP-13) is as follows: $4 \mathrm{~g}$ of $\mathrm{PF}_{0.13} \mathrm{~T}_{0.87} \mathrm{M}$ (or PFTM-13) was dissolved in $40 \mathrm{~mL}$ of DMSO at $80^{\circ} \mathrm{C}$ with $1 \mathrm{~mL}$ of TFA as a cosolvent. After PFTM- 13 was completely dissolved in DMSO, the polymer solution was cooled to room temperature. Then, $2.5 \mathrm{~g}$ of potassium carbonate and $2 \mathrm{~mL}$ of $\mathrm{CH}_{3} \mathrm{I}$ (3eq) were added to the above solution. The quaternization reaction was kept at room temperature for $24 \mathrm{~h}$ with a tinfoil covering to avoid light. After reaction, the polymer solution was precipitated in ethyl acetate to obtain a polymer, and then the polymer was filtered and washed twice with DI water to remove residual inorganic salt. Finally, the polymer was dried in a vacuum oven at $80^{\circ} \mathrm{C}$ for $24 \mathrm{~h}$, and $4.8 \mathrm{~g}$ of white PFTP- 13 was obtained. Yield $>90 \% .{ }^{1} \mathrm{H}$ NMR $(600 \mathrm{MHz}$, DMSO, $\delta): 7.5-7.85 \mathrm{ppm}\left(\mathrm{H}_{\mathrm{e}-\mathrm{h}}\right)$, $3.31 \mathrm{ppm}\left(\mathrm{H}_{\mathrm{a}}\right), 3.12 \mathrm{ppm}\left(\mathrm{H}_{\mathrm{c}}\right), 2.90 \mathrm{ppm}\left(\mathrm{H}_{\mathrm{b}}\right)$, and $1.35 \mathrm{ppm}\left(\mathrm{H}_{\mathrm{d}}\right)$ (Supplementary Fig. 1b). The synthesis procedure of PFBP-14 is similar to PFTP-13.

\section{Synthesis of poly(fluorene $\mathbf{N}$-methylpiperidine-co-nonafluoride) copolymer} (PFMN-x) and PFPN-x. A typical synthesis procedure of PFMN-85 is as follows: $1.94 \mathrm{~g}$ of $9,9^{\prime}$-dimethylfluorene (10 mmol), $1.28 \mathrm{~mL}$ of 1-methyl-4-piperidone (0.98 mL, $8.5 \mathrm{mmol}), 1,1,1,2,2,4,5,5,5$-nonafluoro-4-(trifluoromethyl)pentan-3-one $(0.296 \mathrm{~mL}, 1.5 \mathrm{mmol})$, and $8.7 \mathrm{~mL}$ of $\mathrm{CH}_{2} \mathrm{Cl}_{2}$ were added into a three-necked reactor with mechanical stirring. TFA $(1.2 \mathrm{~mL})$ and TFSA $(8 \mathrm{~mL})$ were slowly added into the above solution at $-3^{\circ} \mathrm{C}$. The color of the above solution immediately became dark red at the beginning, and the reaction was kept at $-3^{\circ} \mathrm{C}$ with continuous stirring for $6 \mathrm{~h}$. Subsequently, the polymer solution was precipitated in a $1 \mathrm{M} \mathrm{NaOH}$ solution and was carefully washed several times in DI water until the $\mathrm{pH}$ was neutral. Finally, the polymer was dried in a vacuum oven at $80{ }^{\circ} \mathrm{C}$ to obtain a yellow PFMN-85. Yield: $\sim 70 \%$.

Then, $1 \mathrm{~g}$ of PFMN-85 was dissolved in $30 \mathrm{~mL}$ of DMSO to form a homogeneous solution. Next, $1 \mathrm{~mL}$ of $\mathrm{CH}_{3} \mathrm{I}$ (>3eq) was added to the above solution. The quaternization reaction was kept at room temperature for $24 \mathrm{~h}$ with a tinfoil covering to avoid light. After the reaction, the polymer solution was precipitated in ethyl acetate and was washed twice in DI water. Finally, the polymer was dried in a vacuum oven at $80{ }^{\circ} \mathrm{C}$ for $24 \mathrm{~h}$. Yellow PFPN- 85 powder was obtained. Yield $\sim 0 \% .{ }^{1} \mathrm{H}$ NMR (600 MHz, DMSO, $\delta): 7.2-7.81 \mathrm{ppm}\left(\mathrm{H}_{\mathrm{e}-\mathrm{g}}\right), 3.31 \mathrm{ppm}\left(\mathrm{H}_{\mathrm{a}}\right) 3.12 \mathrm{ppm}\left(\mathrm{H}_{\mathrm{c}}\right), 2.85 \mathrm{ppm}$ $\left(\mathrm{H}_{\mathrm{b}}\right)$, and $1.35 \mathrm{ppm}\left(\mathrm{H}_{\mathrm{d}}\right)$ (Supplementary Fig. 10).

Membrane casting and ion exchange. $1 \mathrm{~g}$ of PFTP-13 polymer was dissolved in $29 \mathrm{~g}$ DMSO to prepare a $3.33 \mathrm{wt} \%$ polymer solution. Subsequently, the polymer solution was collected into a syringe and filtered by a $0.45 \mu \mathrm{m}$ filter, and then the solution was cast into a $14 \times 21 \mathrm{~cm}$ glass plate. The polymer solution was dried in an oven at $90^{\circ} \mathrm{C}$ for $24 \mathrm{~h}$ to slowly remove the solvents, and then a visible membrane was heated at $140^{\circ} \mathrm{C}$ for another $12 \mathrm{~h}$ under vacuum to remove the solvents. Finally, the membrane was peeled off from the glass plate, resulting in a film with a thickness of $20 \pm 5 \mu \mathrm{m}$.

PFTP-13 membranes were soaked in $1 \mathrm{M} \mathrm{NaOH}, 1 \mathrm{M} \mathrm{NaCl}$, and $1 \mathrm{M} \mathrm{NaCO}_{3}$, respectively, at $60^{\circ} \mathrm{C}$ for $24 \mathrm{~h}$ for ion-exchange to $\mathrm{OH}^{-}, \mathrm{Cl}^{-}$, and $\mathrm{CO}_{3}{ }^{2-}$ forms, respectively. After ion exchange, the color of the PFTP-13 membrane became fainter in the $\mathrm{Cl}^{-}$form and then colorless in $\mathrm{OH}^{-}$and $\mathrm{CO}_{3}{ }^{2-}$ forms.

${ }^{1} \mathbf{H}$ nuclear magnetic resonance. The chemical structures of AEPs were confirmed by ${ }^{1} \mathrm{H}$ NMR (VNMRS $600 \mathrm{MHz}$, Varian, CA, USA). $\mathrm{d}_{6}$-DMSO was used as a solvent with a standard chemical shift of $2.50 \mathrm{ppm}$. Then, $10 \%$ TFA was added to ${ }^{1} \mathrm{H}$ NMR samples to eliminate the water peak effect (3.34 ppm).
Solubility testing. The solubilities of the polymers were measured in DMSO, DMF, NMP, and DMAc. Moreover, the solubility of the AEI solution (5\% DMSO) was measured in isopropanol (IPA)/deionized (DI) water (10 to 1).

IEC, WU, SR, and ion conductivity $(\boldsymbol{\sigma})$. The IEC values of the AEIs were calculated by ${ }^{1} \mathrm{H}$ NMR through the relative integral area between the aromatic and methyl protons. The WU and SR of membranes were measured in $\mathrm{OH}^{-}$and $\mathrm{Cl}^{-}$ forms. After ion exchange, a membrane in a specific form was washed with DI water several times, and then the hydrated membrane was wiped quickly using a filter paper to remove the surface water. The weight $\left(m_{\text {wet }}\right)$ and unidirectional length $\left(L_{\text {wet }}\right)$ of the wet membrane were recorded. Then, the membrane was dried in a vacuum oven to constant weight by covering it with a filter paper to avoid membrane shrinkage. Subsequently, the dry weight $\left(m_{\mathrm{dry}}\right)$ and the length $\left(L_{\mathrm{dry}}\right)$ of the membrane were recorded immediately. In-plane and through-plane SR were measured. WU and SR were calculated according to the following equations:

$$
\begin{gathered}
\mathrm{WU}(\%)=\frac{m_{\mathrm{wet}}-m_{\mathrm{dry}}}{m_{\mathrm{dry}}} \times 100 \% \\
\mathrm{SR}(\%)=\frac{L_{\mathrm{wet}}-L_{d r y}}{L_{\mathrm{dry}}} \times 100 \%
\end{gathered}
$$

The ion conductivity of AEMs was measured using a four-probe method by an AC impedance analyzer (VSP and VMP3 Booster, Bio-Logic SAS, Grenoble, France) over the frequency range from 0.1 to $100 \mathrm{kHz}$. AEM samples in different forms were cut into $1 \times 3 \mathrm{~cm}$ rectangular shapes (width $=1 \mathrm{~cm}$ ), and then the membranes were fixed between two Pt wire electrodes in a fuel cell test station (CNL, Energy Co., Seoul, Korea). The distance $(L)$ between the two electrolytes was $1 \mathrm{~cm}$. The thickness $(d)$ of the membrane sample was measured using a micrometer caliper. In-plane ion conductivity $(\sigma)$ was measured at fully hydrated conditions $(\mathrm{RH}=100 \%)$ at elevated temperatures, and the resistance $(R)$ of the membrane was recorded. The ion conductivity was calculated from the following equation:

$$
\sigma=\frac{d}{R L W}
$$

Hydration number $(\lambda)$, which represents the number of water molecular per $\mathrm{OH}^{-}$, was calculated using the following equation:

$$
\lambda=\frac{\mathrm{WU} \times 10}{\mathrm{IEC} \times 18}
$$

Dynamic vapor sorption (DVS). The water sorption of AEM samples at different RHs was measured by a DVS (Surface Measurement Systems, UK) instrument at $25^{\circ} \mathrm{C}$. AEM samples were dried in a vacuum oven at $100^{\circ} \mathrm{C}$ to remove residual water before testing. During testing, RH was automatically increased from $0 \%$ to $90 \%$ with six steps $(0 \%, 18 \%, 36 \%, 54 \%, 72 \%, 90 \%)$, and then decreased from $90 \%$ to $0 \%$ step by step, and every RH stage was stable for $1 \mathrm{~h}$ to reach water equilibrium.

DFT calculations. Spin-polarized DFT calculations were performed for estimating the adsorption energy of 9,9-dimethylfluorene-dimethylpiperidinium (FL-DMP) and biphenyl-dimethylpiperidinium (BP-DMP) on the surfaces of Pt (111) and $\mathrm{Pt}-\mathrm{Ru}$ (111) using the Vienna Ab initio Software Package (VASP) code, which is based on first principles. The Perdew-Burke-Ernzerhof (PBE) approach within the generalized gradient approximation (GGA) was adopted to examine the electronic exchange correlation function of the interacting electrons. Input parameters were set as follows: energy cutoff $(400 \mathrm{eV})$, energy criteria $\left(10^{-5} \mathrm{eV}\right)$, force criteria $(0.05 \mathrm{eV} / \AA)$, smearing method (Methfessel-Paxton), and broadening width $(0.2$ $\mathrm{eV})$. In this study, adsorption reactions were described as a large scaled unit cell ( $a: 22 \AA, b: 22 \AA, c: 30 \AA$ ) to avoid direct interactions between the periodic images. The calculated adsorption energy was determined from the equation below:

$$
\triangle E_{\text {ad }}=E_{\text {s+ad }}-\left[E_{\mathrm{s}}+E_{\text {ad }}\right]
$$

Here, $\Delta E_{\text {ad }}$ denotes the adsorption energy of the molecule on the catalyst surface. $E_{\mathrm{s}+\text { ad }}$ denotes the total energy of the adsorbed system. $E_{\mathrm{s}}$ denotes the total energy of the catalyst, and $E_{\text {ad }}$ denotes the total energy of the adsorbates. Different adsorption directions of ionomers on the surface of catalysts were considered to compare the optimized adsorption energies of phenyl and ammonium groups.

Torsional rotation calculation. The structural models were constructed by Materials Studio 8.0 (Accelrys). Dihedral angles in the optimized geometry were determined by using the Dmol3 module (GGA/BLYP method and DND basis set). The relative energy variation of highlighted bonds with the torsional rotation angles was measured by the conformers package in Materials Studio 8.0. Energy minimizations of the structures of each conformer generated were done by using the Forcite Module (forcefield assigned COMPASS and Smart algorithm for iterations).

Mechanical properties and thermal stability. A universal testing machine (UTM, AGS-J 500N, Shimadzu, Japan) was used for measuring the mechanical properties of membrane samples. The TSs and elongations at break (EB) of PFBP-14, PFBP-0, 
PFTP-13, PFTP-0, and commercial FAA-3-20 membranes in halogen form were measured in the dry state. All membrane samples were cut into a dumbbell shape $(2 \times 10 \mathrm{~mm})$, and the stretching rate was $1 \mathrm{~mm} / \mathrm{min}$. The thickness of the membranes was recorded using micrometer-scale calipers. In addition, the mechanical properties of PFTP-13 and PFTP- 0 membranes in different forms and at different temperatures were also investigated. Moreover, the TS and EB of the PFTP-13 membrane after in-situ stability testing was investigated.

The thermal stabilities of AEPs were measured using a thermogravimetric analysis instrument (TGA, Q500, TA Instrument, USA) connected to a mass spectrometer (MS, ThermoStar" GSD 301T, Pfeiffer Vacuum GmbH, Germany). The temperature was increased from 30 to $800{ }^{\circ} \mathrm{C}$ at a $10^{\circ} \mathrm{C} / \mathrm{min}$ ramping rate under a nitrogen atmosphere. Mass spectroscopy was used to detect the thermally decomposed species released from AEPs at related temperatures.

Dynamic mechanical analysis (DMA). DMA (Q800, TA Instrument, DE, USA) was employed to measure the glass-transition $\left(T_{\mathrm{g}}\right)$ temperature, $\mathrm{SM}$, and loss modulus (LM) of AEPs. Specifically, all membrane samples were cut into a $0.9 \times$ $2 \mathrm{~cm}$ shape and were fixed with tension clamps in the DMA system. DMA testing was performed with a $1 \mathrm{~Hz}$ single-frequency strain mode, a preload force of $0.01 \mathrm{~N}$ and a force track of $125 \%$ under a nitrogen atmosphere. The target temperature was set to $450^{\circ} \mathrm{C}$ along with a $10^{\circ} \mathrm{C} / \mathrm{min}$ ramping rate.

Intrinsic viscosity. The intrinsic viscosity $([\mathrm{n}])$ of AEPs was measured using a Ubbelohde viscometer in a DMSO solution at $25^{\circ} \mathrm{C}$. The viscometry system is composed of a Schott Viscosystem (AVS 370, Germany), Ubbelohde viscometer (SI Analytics, Type 530 13: Capillary No. Ic, $K=0.03$ ) and piston buret (TITRONIC universal). The polymer solution was gradually diluted into five different concentrations, and the efflux time was automatically and repetitively recorded by the system five times. The reduced $\left(\eta_{\text {red }}\right)$, inherent $\left(\eta_{\text {inh }}\right)$, and intrinsic viscosities can be calculated using the following equations:

$$
\begin{gathered}
\eta_{\text {red }}=\left(\frac{t_{1}}{t_{0}}-1\right) / c \\
\eta_{\text {inh }}=\left(\ln \frac{t_{1}}{t_{0}}\right) / c
\end{gathered}
$$

Here, $t_{1}$ is the efflux time of a polymer solution, $t_{0}$ is the efflux time for a DMSO solution, and $c$ is the concentration of the polymer solution. In a plot of $\eta$ versus $c$, the $y$-intercept was obtained by extrapolating the $\eta_{\text {red }}$ and $\eta_{\text {inh }}$ to $c=0$. The intrinsic viscosity was obtained by calculating the average of the obtained $y$-intercept values.

Differential scanning calorimetry. DSC (Q20, TA Instrument, DE, USA) was employed to determine the number of free water molecules $\left(N_{\text {free }}\right)$ and bound water molecules $\left(N_{\text {bound }}\right)$ present on the AEMs in $\mathrm{OH}^{-}$form. DSC analysis was performed with an aluminum pan under a $50 \mathrm{~mL} \mathrm{~min}^{-1}$ nitrogen flow rate, and the heating temperature was gradually increased from -55 to $20^{\circ} \mathrm{C}$ along with a $3{ }^{\circ} \mathrm{C} \mathrm{min}-1$ ramping rate. $N_{\text {free }}$ and $N_{\text {bound }}$ were determined by the following equations:

$$
\begin{gathered}
\lambda=N_{\text {free }}+N_{\text {bound }} \\
N_{\text {free }}=\frac{H_{\mathrm{f}} / H_{\text {ice }}}{\left(M_{\text {wet }}-M_{\text {dry }}\right) / M_{\text {wet }}} \times \lambda
\end{gathered}
$$

Here, $H_{\mathrm{f}}$ is the enthalpy obtained by the integration of the freezing peak calculated from the DSC program. $H_{\text {ice }}$ is the enthalpy of water fusion. $M_{\text {wet }}$ and $M_{\text {dry }}$ are wet and dry masses of a membrane sample, respectively.

$$
H_{\text {ice }}=H_{\text {ice }}^{\mathrm{o}}-\triangle C_{p} \Delta T_{\mathrm{f}}
$$

where $\Delta C_{p}$ is the difference between the specific heat capacity of liquid water and ice. $\Delta T_{\mathrm{f}}$ is the freezing point depression.

Gas permeability. $\mathrm{H}_{2}, \mathrm{O}_{2}$, and water vapor permeabilities of PFTP-13, PFBP-14, PFTP-0, PFBP-0, commercial FAA-3-20 and Nafion 212 membranes were performed using a laboratory made gas permeability testing system (Supplementary Fig. 30) connected with a gas chromatograph (GC, 490 Micro GC, Agilent Technologies, USA) and two mass flow controllers (MFC, M3030V, Line Tech, Korea) operating at different $\mathrm{RHs}$ (from $0 \%$ to $90 \% \mathrm{RH}$ ) at $60^{\circ} \mathrm{C}(\mathrm{T}$ ) under a $2.2 \mathrm{bar}$ unilateral back pressure ${ }^{47,48}$. The gas permeability $(P)$ can be calculated by the following equation:

$$
P=\frac{V M_{\text {gas }} d}{P_{\text {feed }} R T A \rho} \frac{d_{\mathrm{p}}}{d_{\mathrm{t}}}
$$

Here, $A\left(4.9 \mathrm{~cm}^{2}\right)$ and $d(\mu \mathrm{m})$ represent the effective area and thickness of membrane samples, respectively. $P_{\text {feed }}$ and $M_{\text {gas }}\left(\mathrm{g} \mathrm{mol}^{-1}\right)$ are the pressures of each gas $(760 \mathrm{mmHg})$ and molecular weight of the permeating gas, respectively. $V\left(\mathrm{~cm}^{3}\right)$ is the volume of the measuring device at the bottom of the membrane samples. $\rho\left(\mathrm{g} \mathrm{cm}^{-3}\right)$ and $R\left(\mathrm{~L} \mathrm{mmHg} \mathrm{K}^{-1} \mathrm{~mol}^{-1}\right)$ are the densities of the permeating gas and the gas constant, respectively. $\frac{d_{\mathrm{p}}}{d_{\mathrm{t}}}$ is the slope that can be plotted from a change in permeated gas pressure as a function of time. The unit of $P$ is Barrer where 1 Barrer $=10^{-10} \mathrm{~cm}^{3}$ (STP) $\mathrm{cm} \mathrm{cm}^{-2} \mathrm{~s}^{-1} \mathrm{~cm} \mathrm{Hg}^{-1}$

Morphology analysis. The surface and cross-section morphologies of AEMs and MEAs were observed using a scanning electron microscope (SEM, FE-SEM S- 4800 , Hitachi, Japan) at $15 \mathrm{kV}$. Membrane and MEA samples for observing the crosssection morphologies were fractured in liquid nitrogen, and all samples were coated with a thin platinum layer using an ion sputtering system (E-1045, Hitachi). Atomic force microscopy (AFM) was used to observe the surface microphase separation of AEMs on a MultiMode 8 AFM (Veeco) with a NanoScope V controller. AEMs were tested in $\mathrm{OH}^{-}$form in the dry state.

Fuel cell testing. PFTP-13, PFTP-0, and commercial FAA-2-30 membranes were selected as AEMs. PFTP-13, PFBP-14, PFBP-0, PFTP-0, PFPN-100, PFPN-85, and FuMA-Tech Fumion ionomers were used as AEIs. Pt/C (Tanaka Kikdfinzoku Kogyo-TKK, 46.6 wt\% Pt/C), Pt/C (Johnson Matthey HiSpec 4000, $40 \mathrm{wt} \% \mathrm{Pt} / \mathrm{C}$ ), Pt-Ru/C (Johnson Matthey HiSpec 10,000, $40 \mathrm{wt} \% \mathrm{Pt}$ and $20 \mathrm{wt} \% \mathrm{Ru})$ and home-made Co@C/C (40 wt\% Co) were employed as catalysts. AEIs were dissolved in DMSO to prepare a $5 \%$ polymer solution, and then the polymer solution was filtered using a $0.45 \mu \mathrm{m}$ PTFE filter. The catalyst slurry was prepared by adding the $5 \%$ AEIs/DMSO solution and catalysts into IPA/DI water (10 to 1$)$, and then the slurry was sonicated for $1 \mathrm{~h}$. Subsequently, the catalyst slurry was sprayed onto both sides of AEMs ( $\mathrm{I}^{-}$form) using an airbrush to produce $5 \mathrm{~cm}^{2}$ CCM. $12.5 \mathrm{mg}$ Hispec Pt/C, or $8.33 \mathrm{mg} \mathrm{Pt}-\mathrm{Ru} / \mathrm{C}$, or $11.1 \mathrm{mg}$ TKK Pt/C can produce the catalyst loading of $0.4 \pm 0.05 \mathrm{mg} \mathrm{cm}^{-2}$ in a dry CCM. The ratio of catalysts to ionomers is $3.33: 1$. CCMs were immersed in $1 \mathrm{M} \mathrm{NaOH}$ at room temperature overnight, and they were then washed with DI water three times. CCMs in the wet state were directly assembled with two gas diffusion layers (GDLs), fluorinated ethylene propylene (FEP) gaskets, and graphite bipolar plates with a $5 \mathrm{~cm}^{2}$ flow field to obtain a complete AEMFC using a torque of $70 \mathrm{in}-\mathrm{lb}$. The actual catalyst loading of MEAs was slightly adjusted by the area swelling of wet CCMs.

AEMFC performance was measured using a fuel cell test station (CNL, Seoul, Korea). Single cells were activated by scanning the current from 0 to $3 \mathrm{~A} \mathrm{~cm}^{-2}$ with a $1000 \mathrm{~mL} \mathrm{~min}^{-1}$ flow rate at $80^{\circ} \mathrm{C}$ for two cycles without backpressure, and the polarization curve and power density curve were recorded after activation. Fuel cell performance was tested under different conditions, including temperature, $\mathrm{RH}$, back pressure, flow rate, and feed gas.

Ex-situ and in-situ durability. The ex-situ durability of the PFTP-13 membrane was measured in 1,5 , and $10 \mathrm{M} \mathrm{NaOH}$ at $80^{\circ} \mathrm{C}$ for $2000 \mathrm{~h}$. The degradation ratio of PFTP- 13 was calculated by the changes in chemical structure detected by ${ }^{1} \mathrm{H}$ NMR and $\mathrm{Cl}^{-}$conductivity at room temperature. Changes in the mechanical properties and thermal stability were also investigated after alkaline treatment in $10 \mathrm{M} \mathrm{NaOH}$ at $80^{\circ} \mathrm{C}$ for $168 \mathrm{~h}$. Moreover, the in-situ durability was measured at a $0.2 \mathrm{~A} \mathrm{~cm}^{-2}$ current density at $70^{\circ} \mathrm{C}$ under $\mathrm{H}_{2}-\mathrm{O}_{2}$ conditions based on A/C PFBP-14 ionomers and a PFTP-13 membrane.

\section{Data availability}

The data that support the plots within this paper and other findings of this study are available from the corresponding author upon reasonable request.

Received: 29 September 2020; Accepted: 22 March 2021; Published online: 22 April 2021

\section{References}

1. Park, C. H. et al. Nanocrack-regulated self-humidifying membranes. Nature 532, 480-483 (2016).

2. Hassan, N. U. et al. Achieving high-performance and $2000 \mathrm{~h}$ stability in anion exchange membrane fuel cells by manipulating ionomer properties and electrode optimization. Adv. Energy Mater. 10, 2001986 (2020).

3. Peng, X. et al. Using operando techniques to understand and design high performance and stable alkaline membrane fuel cells. Nat. Commun. 11, 3561 (2020).

4. Ramesh, K. S. et al. Synthesis of $\mathrm{CeO}_{x}$-decorated $\mathrm{Pd} / \mathrm{C}$ catalysts by controlled surface reactions for hydrogen oxidation in anion exchange membrane fuel cells. Adv. Funct. Mater. 30, 2002087 (2020).

5. Lee, K. H. et al. Highly conductive and durable poly(arylene ether sulfone) anion exchange membrane with end-group cross-linking. Energy Environ. Sci. 10, 275-285 (2017).

6. Chen, N. J. \& Lee, Y. M. Anion Exchange polyelectrolytes for membranes and ionomers. Prog. Polym. Sci. 113, 101345 (2021).

7. Thompson, S. T., Peterson, D., Ho, D. \& Papageorgopoulos, D. Perspectivethe next decade of AEMFCs: near-term targets to accelerate applied R\&D. $J$. Electrochem. Soc. 167, 084514 (2020). 
8. Meeka, K. M. et al. High-throughput anion exchange membrane characterization at NREL. ECS Trans. 92, 723-731 (2019).

9. Shin, D. W., Guiver, M. D. \& Lee, Y. M. Hydrocarbon-based polyme electrolyte membranes: importance of morphology on ion transport and membrane stability. Chem. Rev. 117, 4759-4805 (2017).

10. Park, E. J. et al. Alkaline stability of quaternized Diels-Alder polyphenylenes. Macromolecules 52, 5419-5428 (2019).

11. Chen, N. J., Long, C., Li, Y., Lu, C. \& Zhu, H. Ultrastable and high ionconducting polyelectrolyte based on six-membered $\mathrm{N}$-spirocyclic ammonium for hydroxide exchange membrane fuel cell applications. ACS Appl. Mater. Interfaces 10, 15720-15732 (2018).

12. Wang, L. et al. Non-fluorinated pre-irradiation-grafted (peroxidated) LDPEbased anion-exchange membranes with high performance and stability. Energy Environ. Sci. 10, 2154-2167 (2017).

13. Zheng, Y. et al. Quantifying and elucidating the effect of $\mathrm{CO}_{2}$ on the thermodynamics, kinetics and charge transport of AEMFCs. Energy Environ. Sci. 12, 2806-2819 (2019).

14. Cha, M. S. et al. Poly(carbazole)-based anion-conducting materials with high performance and durability for energy conversion devices. Energy Environ. Sci. 13, 3633-3645 (2020).

15. Fan, J. et al. Poly(bis-aryl imidazoliums) possessing high hydroxide ion exchange capacity and high alkaline stability. Nat. Commun. 10, 2306 (2019).

16. Wright, A. G. et al. Hexamethyl-p-terphenyl poly(benzimidazolium): a universal hydroxide-conducting polymer for energy conversion devices. Energy Environ. Sci. 9, 2130-2142 (2016).

17. (a)Wang, J. et al. Poly(aryl piperidinium) membranes and ionomers for hydroxide exchange membrane fuel cells. Nat. Energy 4, 392-398 (2019). (b) Wang, T. et al. High-performance hydroxide exchange membrane fuel cells through optimization of relative humidity, backpressure and catalyst selection. J. Electrochem. Soc. 166, F3305-F3310 (2019).

18. $\mathrm{Gu}, \mathrm{S}$. et al. A soluble and highly conductive ionomer for high-performance hydroxide exchange membrane fuel cells. Angew. Chem. Int. Ed. Engl. 48, 6499-6502 (2009).

19. Zhang, B. et al. Tertiary sulfonium as a cationic functional group for hydroxide exchange membranes. RSC Adv. 2, 12683-12685 (2012).

20. Chen, N. J. et al. Cobaltocenium-containing polybenzimidazole polymers for alkaline anion exchange membrane applications. Polym. Chem. 8, 1381-1392 (2017).

21. Zha, Y., Disabb-Miller, M. L., Johnson, Z. D., Hickner, M. A. \& Tew, G. N. Metal-cation-based anion exchange membranes. J. Am. Chem. Soc. 134, 4493-4496 (2012).

22. Kim, Y. et al. Ionic highways from covalent assembly in highly conducting and stable anion exchange membrane fuel cells. J. Am. Chem. Soc. 141, 18152-18159 (2019).

23. Liang, $\mathrm{X}$. et al. Ionomer cross-linking immobilization of catalyst nanoparticles for high performance alkaline membrane fuel cells. Chem. Mater. 31, 7812-7820 (2019).

24. Olsson, J. S., Pham, T. H. \& Jannasch, P. Poly(arylene piperidinium) hydroxide ion exchange membranes: synthesis, alkaline stability, and conductivity. Adv. Funct. Mater. 28, 1702758 (2018).

25. You, W., Padgett, E., MacMillan, S. N., Muller, D. A. \& Coates, G. W. Highly conductive and chemically stable alkaline anion exchange membranes via ROMP of trans-cyclooctene derivatives. Proc. Natl Acad. Sci. USA 116, 9729-9734 (2019).

26. Chu, X., Liu, L., Huang, Y., Guiver, M. D. \& Li, N. Practical implementation of bis-six-membered $\mathrm{N}$-cyclic quaternary ammonium cations in advanced anion exchange membranes for fuel cells: synthesis and durability. J. Membr. Sci. 578, 239-250 (2019).

27. Hibbs, M. R. Alkaline stability of poly(phenylene)-based anion exchange membranes with various cations. J. Polym. Sci. Part B 51, 1736-1742 (2013)

28. Yang, Z. et al. Highly conductive anion-exchange membranes from microporous Troger's base polymers. Angew. Chem. Int. Ed. Engl. 55, 11499-11502 (2016).

29. Wang, L., Peng, X., Mustain, W. E. \& Varcoe, J. R. Radiation-grafted anionexchange membranes: the switch from low- to high-density polyethylene leads to remarkably enhanced fuel cell performance. Energy Environ. Sci. 12, 1575-1579 (2019).

30. Omasta, T. J. et al. Beyond catalysis and membranes: visualizing and solving the challenge of electrode water accumulation and flooding in AEMFCs. Energy Environ. Sci. 11, 551-558 (2018).

31. Mandal, M. et al. The importance of water transport in high conductivity and high-power alkaline fuel cells. J. Electrochem. Soc. 167, 054501 (2019).

32. Li, Q. et al. The Comparability of Pt to Pt-Ru in catalyzing the hydrogen oxidation reaction for alkaline polymer electrolyte fuel cells operated at 80 degrees C. Angew. Chem. Int. Ed. Engl. 58, 1442-1446 (2019).

33. Huang, G. et al. Composite poly(norbornene) anion conducting membranes for achieving durability, water management and high power $\left(3.4 \mathrm{~W} / \mathrm{cm}^{2}\right)$ in hydrogen/oxygen alkaline fuel cells. J. Electrochem. Soc. 166, F637-F644 (2019).

34. Maurya, S. et al. Rational design of polyaromatic ionomers for alkaline membrane fuel cells with $>1 \mathrm{~W} \mathrm{~cm}^{-2}$ power density. Energy Environ. Sci. 11, 3283-3291 (2018)

35. Lee, W.-H. et al. Poly(terphenylene) anion exchange membranes: the effect of backbone structure on morphology and membrane property. ACS Macro Lett. 6, 566-570 (2017).

36. Peng, H. et al. Alkaline polymer electrolyte fuel cells stably working at $80^{\circ} \mathrm{C}$. $J$. Power Sources 390, 165-167 (2018).

37. Matanovic, I. et al. Adsorption of polyaromatic backbone impacts the performance of anion exchange membrane fuel cells. Chem. Mater. 31, 4195-4204 (2019).

38. Maurya, S., Fujimoto, C. H., Hibbs, M. R., Narvaez Villarrubia, C. \& Kim, Y. S. Toward improved alkaline membrane fuel cell performance using quaternized aryl-ether free polyaromatics. Chem. Mater. 30, 2188-2192 (2018).

39. Park, E. J. et al. How does a small structural change of anode ionomer make a big difference in alkaline membrane fuel cell performance? J. Mater. Chem. A 7, 25040-25046 (2019).

40. Guiver, M. D. \& Lee, Y. M. Polymer rigidity improves microporous membranes. Science 339, 284-285 (2013).

41. Eriksson, B. et al. Quantifying water transport in anion exchange membrane fuel cells. Int. J. Hydrogen Energy 44, 4930-4939 (2019).

42. Yassin, K., Rasin, I. G., Brandon, S. \& Dekel, D. R. Quantifying the critical effect of water diffusivity in anion exchange membranes for fuel cell applications. J. Membr. Sci. 608, 118206 (2020).

43. Park, H. B. et al. Polymers with cavities tuned for fast selective transport of small molecules and ions. Science 318, 254-258 (2007).

44. Peng, $\mathrm{X}$. et al. Nitrogen-doped carbon- $\mathrm{CoO}_{\mathrm{x}}$ nanohybrids: a precious metal free cathode that exceeds $1.0 \mathrm{Wcm}^{-2}$ peak power and $100 \mathrm{~h}$ life in anion exchange membrane fuel cells. Angew. Chem. Int. Ed. 131, 1058-1063 (2019).

45. Omasta, T. J. et al. Strategies for reducing the PGM loading in high power AEMFC anodes. J. Electrochem. Soc. 165, F710-F717 (2018)

46. Leonard, D. P. et al. Asymmetric electrode ionomer for low relative humidity operation of anion exchange membrane fuel cells. J. Mater. Chem. A 8, 14135-14144 (2020)

47. Chen, G. Q., Scholes, C. A., Qiao, G. G. \& Kentish, S. E. Water vapor permeation in polyimide membranes. J. Membr. Sci. 379, 479-487 (2011).

48. Choi, J. et al. Application of spirobiindane-based microporous poly(ether sulfone)s as polymeric binder on solid alkaline exchange membrane fuel cells. J. Membr. Sci. 568, 67-75 (2018).

49. Wang, Y. et al. Pt-Ru catalyzed hydrogen oxidation in alkaline media: oxophilic effect or electronic effect? Energy Environ. Sci. 8, 177-181 (2015).

50. Zhu, L. et al. Multication side chain anion exchange membranes. Macromolecules 49, 815-824 (2016).

51. Gao, X. et al. Enhanced water transport in AEMs based on poly (styrene-ethylene-butylene-styrene) triblock copolymer for high fuel cell performance. Polym. Chem. 10, 1894-1903 (2019).

52. Jeon, J. Y. et al. Synthesis of aromatic anion exchange membranes by Friedel-Crafts bromoalkylation and cross-linking of polystyrene block copolymers. Macromolecules 52, 2139-2147 (2019).

\section{Acknowledgements}

This research was supported by the Technology Development Program to Solve Climate Change through the National Research Foundation of Korea (NRF) funded by the Ministry of Science and ICT (NRF-2018M1A2A2061979) and Material Component Technology Development (20010955) through the Korea Evaluation Institute of Industrial Technology (KEIT) funded by the Ministry of Trade, Industry and Energy, South Korea.

\section{Author contributions}

Y.M.L. and N.J.C. conceived of the idea. N.J.C. wrote the draft. Y.M.L. guided the work and edited the manuscript. N.J.C. synthesized the polymers, fabricated the membranes, and measured ion conductivity and alkaline stability. N.J.C., H.H.W., and H.M.K. performed TGA and mechanical property measurements. H.H.W. and H.M.K. tested the intrinsic viscosity and performed DSC and DMA measurements. Y.-C.C. and E.S.S. performed the DFT calculations. H.H.W. performed SEM and TEM measurements. S.P.K. prepared MEA. N.J.C. and S.P.K. tested fuel cells and in-situ durability. C.H. and N.J.C. performed AFM measurements. W.H.L. and J.Y.B. tested water and gas permeabilities. Torsional rotation calculations were done by Y.Z. Co@C/C cathode-based AEMFCs were measured by S.J.Y. and J.-H.J.

\section{Competing interests}

The authors declare no competing interests. 


\section{Additional information}

Supplementary information The online version contains supplementary material available at https://doi.org/10.1038/s41467-021-22612-3.

Correspondence and requests for materials should be addressed to Y.M.L.

Peer review information Nature Communications thanks the anonymous reviewer(s) for their contribution to the peer review of this work. Peer reviewer reports are available.

Reprints and permission information is available at http://www.nature.com/reprints

Publisher's note Springer Nature remains neutral with regard to jurisdictional claims in published maps and institutional affiliations. (c) (1) Open Access This article is licensed under a Creative Commons Attribution 4.0 International License, which permits use, sharing, adaptation, distribution and reproduction in any medium or format, as long as you give appropriate credit to the original author(s) and the source, provide a link to the Creative Commons license, and indicate if changes were made. The images or other third party material in this article are included in the article's Creative Commons license, unless indicated otherwise in a credit line to the material. If material is not included in the article's Creative Commons license and your intended use is not permitted by statutory regulation or exceeds the permitted use, you will need to obtain permission directly from the copyright holder. To view a copy of this license, visit http://creativecommons.org/licenses/by/4.0/.

(c) The Author(s) 2021 